\title{
EFFECT OF POLYMER EMULSION ON THE BEARING CAPACITY OF AEOLIAN SAND UNDER EXTREME CONFINEMENT CONDITIONS
}

\author{
Juana Arias-Trujillo ${ }^{1^{*}}$, Agustin Matías-Sanchez $^{1 * *}$, Blas Cantero ${ }^{1 * * *}$, Susana López-Querol ${ }^{2}$,
}

1: School of Engineering, Department of Construction, University of Extremadura, Avda. de la Universidad, s/n, 10003, Caceres (Spain), Email addresses: *: jariastr@unex.es ${ }^{* *}$ amatias@unex.es; ${ }^{* * *}: \underline{\text { bcanteroch@unex.es; }}$

2: Department of Civil, Environmental and Geomatic Engineering, University College London (UCL), London WC1E 6BT (UK). Tel. N. +44 (0)20 7679 2722, Email address: s.lopezquerol@ul.ac.uk (author for correspondence)

(Declarations of interest: none)

\section{Abstract}

An experimental investigation, aimed at evaluating the improvement of aeolian sand (from Saudi Arabia) when treated with low dosages of a vinyl acrylic (a polymer emulsion), is reported in this paper. Special attention is devoted to the influence of the lateral confinement, particularly in terms of compaction and bearing capacity (represented by CBR), for which a modification of the standard test has been developed trying to simulate extreme confinement conditions. Experimental results demonstrate that this kind of chemical stabilizers can be considered as a suitable alternative for these materials. The main modifications induced in the sand by this additive are highlighted and quantified by means of the modification achieved for different geotechnical properties as well as Scanning Electron Microscope (SEM) and Energy-Dispersive X-Ray Spectroscopy (EDX) analyses.

Keywords: Aeolian sand; Acrylic polymer emulsion; Compaction; Bearing capacity; Confined and Unconfined Conditions; Soil stabilization 


\section{Introduction}

Nowadays, the tremendous growth in many transportation infrastructures under development in arid regions around the world makes it necessary to consider the utilization of aeolian sand for construction purposes. This type of soil is well known as a very particular and challenging material, especially for its use on geotechnical structures as roads and railways embankments. Although this type of soil is a low plasticity granular material (considered as an advantageous property from a geotechnical engineering point of view), it is characterized by both a very uniform particle size distribution (where the fine fraction is clearly predominant), and by the lack of edges in their particles. Because of that, this type of soil is very difficult to compact, and sometimes even impossible, resulting on a very low final bearing capacity on site, unless it is subjected to an improvement treatment, normally by means of stabilization procedures. This problem becomes even worse when this sand is placed as embankment fills with low levels of lateral confinement. These characteristic drawbacks of aeolian sands could be omitted if other suitable alternative materials were available close to the construction site. However, this is neither possible in many places across the world nor convenient from economic or environmental points of view, and the only solution in these cases is often its utilization with a treatment for improving its workability conditions and its engineering performance.

From the physical characterization sides, aeolian sand displays very fine particle sizes (ranging from $0.08 \mathrm{~mm}$ to $0.40 \mathrm{~mm}$, with negligible fines content), quite homogeneous grading curves and rounded shapes [1-12]. The natural water content of these soils is normally very low (between 0 and $4 \%$ ) and its permeability ranges from $3.4 \mathrm{e}-4$ to $1 \mathrm{e}-2 \mathrm{~cm} / \mathrm{s}$, with a maximum water absorption usually lower than $1.0 \%[4,5,7,10]$. Regarding the mineralogy of these materials, quartz is the main component, with some small amounts of feldspars and calcites $[3,5,6,9,10]$. Its specific gravity is ranging between 2.44 to 2.75 in African regions $[3,16,17]$, and between 2.63 to 2.87 in Asiatic areas $[4,8,9,10,12]$.

Regarding its geotechnical properties, this type of soil normally presents a very flat-shaped compaction curve (dry density vs. water content), without a clear optimum, because it has rather similar lowest and highest values, mainly attributed to its high homogeneity $[4,7,8]$. Unlike for most natural soils, in addition to the maximum dry density, it is also possible to find a minimum 
dry density value at very low water contents (around $2 \%-4 \%$ ), which is one of the most singular characteristics of these materials [7]. In general, the range of maximum dry density for aeolian sands reported in the literature, goes from 1.642 to $1.765 \mathrm{~g} / \mathrm{cm} 3$, corresponding to optimum moisture contents values from 11.0 to $14.5 \%[4,6,10,12]$. The bearing capacity of these soils has been scarcely investigated and reported in the literature, since in most of the cases, the conventional CBR test, which is normally complementary to the Modified Proctor test, is replaced by the Unconfined Compressive Strength (UCS), not directly related to the geotechnical performance in transportation infrastructures. Finally, under shearing, this material shows a negligible cohesion and quite significant friction angles, from 39 to 42 degrees $[4,9,10]$. Therefore, according to most of the standards and normative of reference, aeolian sands are very good materials to use in roads and embankments [12]. However, as previously mentioned, when aeolian sand is not enough laterally confined, its geotechnical performance becomes rather poor and unfavorable, and a stabilization procedure is then recommended.

The stabilization techniques of granular materials are well-known in the geotechnical engineering field, cement and bitumen being the most frequently employed additives for this purpose. Plenty of successful experiences on stabilization of aeolian sand with cement have been reported in the literature [13-19]. However, this additive sometimes presents several drawbacks, like its high cost, lack of availability in some regions, or conferring brittle performance with low flexural strength to the treated samples, as well as being not very much environmentally friendly. These problems sometimes make it convenient to explore other suitable alternatives. Among other options, bitumen stabilizations have been demonstrated as a reasonable and logical option, particularly at those places with high availability of petroleum. It is possible to find in the literature a wide collection of researches on bitumen emulsion (including emulsified, cutback and foamed asphalt) as stabilizing material, sometimes accompanied by cement [20-30]. In spite of the success reached with this additive in most of the reported cases, this kind of bitumen stabilization usually requires the addition of other additives or activators, which usually makes it an expensive a complex option.

On the other hand, other alternative additives are in continuous development, aiming at overcoming the main drawbacks identified in the traditional options, although their utilization is still very limited. In such cases, chemical emulsions come into play as a very feasible and reasonable 
cheap solution, since several pieces of research have reported that significant improvements can be achieved with small amounts of such additives [31-39]. In particular, between the great number of available chemical stabilizers, polymer emulsions have been among of the most employed ones along the last decades, utilized as additives alternative to the most traditional ones or in conjunction with them, especially with cement [39]. They are usually named as "non-traditional stabilizers". This kind of additives has been extensively employed for both granular material and other soils with different plasticity. But, in spite of its possibilities, it is currently under research and its application is still far from generalized.

According to Onyejekwe and Ghataora [39], the advantages of using polymer emulsion in soil stabilization are many, as they contribute to the improvement of the geotechnical properties. These researchers employed an interval of dosage ranging from 0.26 to $1.32 \%$, respect to maximum soil dry density, for the stabilization of quarry fines, resulting on the enhancement of the adhesion between soil particles and increment of the compressive, flexural and tensile strengths of the soil, showing also a stable behavior under environmental conditions. Through Scanning Electron Microscope (SEM) analysis, lyengar et al. [37] compared the soil microstructure after the addition of polymer or cement as additives in a subgrade in Qatar, concluding that the polymer stimulates aggregation between particles of soil, although this bonding is not as extended as in the cemented samples. Furthermore, the microstructure of polymer-treated soil becomes denser than the untreated soil but less dense in comparison with the same material when mixed with cement. Similar trends have also been reported by other researchers [39]. The effect of these additives on treated soils can be strongly influenced by stabilizer dosages and different curing conditions [36, 38, 39].

The durability of soils stabilized with polymer under high very moisture content or adverse environmental conditions has been highlighted by different researchers [36, 38, 39]. According to Onyejekwe and Ghataora [39], the total immersion in water of improved specimens is the most severe durability test, since it allows us to track the deterioration of the samples by the action of ponded water. These authors reported that, while untreated specimens were immediately disintegrated upon their immersion, those samples improved with polymer emulsion took longer to lose their strength, with failure times ranging from days to months depending on the dosage of emulsion and the inclusion (or not) of cement as an additional additive. Moreover, they concluded 
that those specimens treated only with polymer emulsion experienced a large deterioration after 7 days of immersion, while those samples treated with a mixture of polymer and cement did not experience failure. However, from the durability point of view, high moisture contents or ponded water are not common environmental conditions in arid areas, which seem to indicate that cement might not be needed at those sites for this type of treatment to guarantee the durability of the improved material. On the contrary, under humid locations, cement is recommended as an additional (or even unique) additive for soil improvement. In any case, a successive drainage system is always an important design recommendation for any geotechnical structure or embankment.

In this paper, the suitability of a vinyl acrylic, polymer emulsion as improvement additive for aeolian sand from Jeddah (Saudi Arabia) is explored. Previous studies reported in the literature about the usage of this non-traditional additive are very scarce, particularly for aeolian sand. The influence of different dosages of polymer emulsion on the compaction and bearing capacity of this material is presented and discussed in depth hereinafter. The corresponding tests developed for this aim are also supported by previous works conducted in the past by the same authors [19]. Different proportions of polymer emulsion have been considered, starting with very low dotation which was progressively increased until reaching the maximum dosage at which the samples were workable in the laboratory. As a result of this process, three dosages were considered: $0.5 \%, 1.0 \%$ and $1.5 \%$ of the dry mass of the sand. Regarding the bearing capacity of the treated soil, particular attention has been devoted to the absence of lateral confinement in the tested samples, and two new specific indices have been employed to quantify the influence of the confinement in performance of the improved material. Scanning Electron Microscope (SEM) images and Energy-Dispersive X-Ray Spectroscopy (EDX) have also been obtained on samples mixed with the three different dosages, aiming at characterizing their resulting microstructure. A

\section{Materials}

\subsection{Aeolian sand}

The aeolian sand tested in this research was collected from Jeddah desert dunes (Arabia Saudi). This soil presents very particular properties which are characteristic of this type of 
materials, fitting well into the typical properties of other aeolian sands previously reported in the literature $[1-12,19]$.

The aeolian sand from Jeddah has a mineralogical composition mostly formed by quarzitic sand $(73.8 \%)$ with a bit of feldspar $(3.3 \%)$ and calcite. Moreover, this sand is a non-plastic material with a very uniform particle size distribution, mainly ranging between 0.08 and $0.63 \mathrm{~mm}$, with fines content as small as $1.38 \%$. This sand is classified as poorly graded (SP) [40]. From the morphology point of view, its coarser fraction (with sizes higher than $0.160 \mathrm{~mm}$ ) consists of particles with rounded shape and no sharp edges, and a very clean microstructure for those ones ranging from 0.26 to $0.767 \mathrm{~mm}$. The finer fraction, in contrast, is more heterogeneous, less rounded, and with some edges, slabs and fractures, likely due to different mechanisms of transportation (Fig. 1). The natural moisture content of this soil was estimated as $0.27 \%$ and its bearing capacity under low-confinement condition is null [19]. The main physical characteristics of this material are summarized in Table 1 and also a detailed characterization is reported in [19].

\subsection{Polymer emulsion}

To meet the main objective of this research, a commercial polymer emulsion has been used as additive [42]. Polymer emulsions are suspensions of synthetic polymers in an aqueous medium [38, 39]. In this research, a vinyl acrylic, polymer emulsion has been employed. The chemical structures of this polymer emulsion consist of molecular chains of linear bonds, crosslinked with other chains or molecular networks that can reach a length of $1,000,000$ molecules, which are much longer than the molecular chains in usual bituminous emulsions, with lengths between 100 and 10,000 molecules. The length of the molecular chains and the capacity of adherence to the soil particles are the main causes identified to explain the high effectiveness of this type of emulsions, which presents a high hardness and stiffer elasticity properties at the same time.

This polymer emulsion is compliant with environmental restrictions since it is harmless to the environment and has been specially developed for different uses such as reduction of dust emissions, as well as control of superficial erosion and disintegration, avoiding the sediment transportation and improving the waterproofing of the surface. This additive presents good properties under different meteorological conditions such as wind, rain, or ultraviolet radiation. 
This emulsion has been employed in many other civil engineering applications as for instance in non-asphalt roads, slope reinforcements, protection of shoulder and ditches of roads, parking, etc. However, it has never been utilized with the aim of improving or stabilizing sand deposits for construction of geo-structures.

On-site, this polymer emulsion has to be mixed with in-situ soil under environment temperature (from 10 to $40^{\circ} \mathrm{C}$ ) and with the water quantity necessary to reach the optimum moisture content. The dosage of polymer emulsion is strongly influenced by the in-situ soil characteristics, the application and the aimed improvement goal. Due to the particularities of this emulsion and its friendly usage features, it seems reasonable to research its possibilities for stabilization of aeolian sands. The main physical and chemical specifications of the employed emulsion are listed in Table 2 [42].

192

\section{Experimental procedures}

The developed experimental testing program was designed for analyzing the improvement induced by the polymer emulsion in the compaction and bearing capacity performances after the stabilization of aeolian sand, paying special attention to the influence of the lateral confinement conditions in the results under of two extreme situations: fully confined and unconfined (or nullconfinement). For achieving this purpose, modifications of the conventional compaction (Modified Proctor, [43]) and bearing capacity tests (CBR, [44]) were developed, the particularities of which are summarized next. The newly designed experimental procedures have already been successfully validated for analyzing the performance of cement-stabilized soils [19]. The experimental works presented in this research were held at the Geotechnical Laboratory at the University of Extremadura (Caceres, Spain).

As previously mentioned, the tests were aimed at investigating the effects of three different dosages of polymer emulsion, $0.5 \%, 1.0 \%$ and $1.5 \%$ respect to the dry mass of soil, for both compaction and bearing capacity performance of the sand, subject to two lateral confinement conditions. The interval of dosages selected is in agreement with previous values reported in the literature [39], starting with a very low value $(0.5 \%)$ to explore the effectiveness of reduced quantities of the polymer. Then, the dosages were increased until the samples were not workable 
and testable anymore due to excessive loss of initial consistency. For this soil, the maximum suitable emulsion content was found to be $1.5 \%$.

For each dosage of polymer emulsion, each lateral confinement condition and each type of experiment, two tests were undertaken to ascertain the repetitiveness of the results. In order to evaluate the improvement induced by the treatment, the corresponding untreated specimens were also tested and the corresponding results are also included throughout the paper for comparison purposes.

The improvement observed in the engineering properties of the stabilized specimens has been supported by a microstructure analysis (SEM and EDX), which reveals the modification in the internal structure due to the polymer emulsion as chemical additive. These analyses took place at the SAIUEx service of the University of Extremadura (Spain).

\subsection{Sample preparation and curing process}

To set up the samples for testing, the initial natural moisture of the soil was determined, as well as the necessary portions of material by quartering bigger samples to achieve representative soil fractions. To guarantee uniform distribution of the polymer into the mass of soil, the calculated amount of polymer dilution was first mixed with the corresponding water content getting a homogenous solution. After that, this was thoroughly mixed with the soil by hand until the distribution of the solution in the soil was totally uniform and the color of the mixture became homogeneous. For the calculation of the final water quantity in each specimen, the water content of the polymer dilution was discounted.

Before developing the bearing capacity tests, a proper curing process was absolutely necessary since the performance of the treated soil is strongly influenced by the moisture content of the specimen $[36,38,39]$, and on the other hand, the maximum contribution of the polymer to the stabilization of the soil is achieved when it has been completely dried. After placing the mixture (soil and solution of water with polymer) into the mold, it was cured at a constant temperature of $40^{\circ} \mathrm{C}$ in an oven, trying to reproduce a usual environment temperature as in desert areas. Those specimens aimed at being subjected to full confinement tests (confined conditions) were maintained into the mold during the curing, whereas the specimens for tests without confinement (unconfined) were cured outside it. For checking the degree of achieved curing, the 
weight of each specimen was controlled on a daily basis until it reached a constant value during three consecutive days. Normally, the opened-mold-specimens took 5 days to complete the drying process, independently of the dosage of additive. However, the closed-mold-specimens took between 10 and 15 days for completing their curing, significantly depending on the dosage of additive.

\subsection{Compaction test and optimum water content}

By means of a variation of the Modified Proctor procedure [43], a set of compaction tests was carried out for the three different contents of polymer emulsion, aiming at establishing the maximum dry density and the corresponding optimum water content for each case, which is necessary to be known in advance in order to prepare the samples for the bearing capacity tests. As previously said, for each dosage, two complete tests were undertaken to guarantee the repetitiveness of the results, which did not result in very different values in any case. The average values of the two tests are finally adopted for each case.

Considering the particularities of the novel procedure developed for analyzing the influence of the lateral confinement in the bearing capacity response of a stabilized soil, which is described in the following section, several modifications were adopted in the laboratory procedures respect to the conventional Modified Proctor test [43]. Thus, the height of the samples was reduced to 76.2 $\mathrm{mm}$, and to keep the same energy of compaction per unitary volume respect to the normalized test, the number of layers was also reduced from five to three. Furthermore, the rest of parameters involved in the test, such as diameter of the mold $(152.5 \mathrm{~mm})$, characteristics of the hammer (50 mm of diameter, $4.535 \mathrm{~kg}$ of mass and $457 \mathrm{~cm}$ of height of fall) and the number of blows by layer (60 blows), were matched to the normalized Modified Proctor procedure [43]. In all cases, the compaction was carried out by means of an automatic compactor and, at least, five water contents were employed in each test to accurately obtain the compaction curve both in the dry and wet sides.

\subsection{Bearing Capacity tests for different degrees of lateral confinement}

According to the main objective of this research, a modification of the standard CBR test [44] 

the addition of different percentages of polymer emulsion can be quantified respect to the nonstabilized soil and, in particular, it can be tested under low or null-confinement condition, which is one of the major drawbacks exhibited by this type of soil in the construction of geo-structures. The bearing capacity tests were developed for the three dosages of polymer emulsion investigated.

As for the compaction test, a reduced height of the CBR mold was also adopted and consequently the number of layers was again reduced to three, maintaining the number of blows by layer equal to 15,30 and 60 respectively for the three specimens necessary in a CBR test. All the tested samples were mixed with the corresponding optimum water content obtained in the previous compaction test, which naturally varies for each percentage of polymer emulsion. The immersion stage, which is sometimes included in a CBR procedure, was omitted because this sand is a non-plastic soil. Before the penetration stage, the specimens were properly cured until reaching a constant mass, which implies that the polymer emulsion was completely dried, and the contribution of the additive to the stabilization of the sand was then assumed maximum in all cases. Since this initial condition was guaranteed in all specimens, the results obtained can be compared and employed as an indicator of the effectiveness of the treatment.

For the penetration stage, a multi-function load frame was used to determinate the CBR values. In this phase, a piston of $50 \mathrm{~mm}$ diameter penetrates into the soil, where the sample is subjected to a vertical overload of $4.5 \mathrm{~kg}$ homogeneously distributed around the penetration area. For the confined condition, the samples were tested inside of the mold during the penetration phase, whereas for reproducing low or null-confined condition, the samples were tested outside the mold, which represents the most critical situation due to the total absence of lateral confinement to the bearing capacity of the soil. From this penetration stage, the corresponding load-displacement curves were obtained for each dosage of polymer emulsion and for each type of extreme confinement conditions. Starting from these curves, the final value of CBR was calculated. As in the case of compaction tests, the untreated sand results have been also 


\subsection{Microstructure Analyses}

Detailed microstructure characterization of the stabilization treatment considered in this research has been developed by means of Scanning Electron Microscope (SEM) and EnergyDispersive X-Ray Spectroscopy (EDX) procedures, both untreated and treated specimens for each dosage of polymer emulsion considered. The changes of the internal microstructure of the soil after the treatment and also the alteration of the chemical composition is analysed and compared for each dosage of polymer emulsion considered, respect to the untreated sand.

The SEM analysis was conducted using a Quanta 3D FEG (FEI) scanning electron microscope, under low vacuum conditions (between 10 to $130 \mathrm{~Pa}$ ). Soil samples not were coated with heavy metal to prevent the alteration of their elemental composition. The magnifications ranged from $30 \mathrm{x}$ to $1280 \mathrm{kx}$. Electron backscatter diffraction (BSED) images have been used to detect contrast between areas with different chemical compositions since heavy elements (high atomic number) appear brighter in the image while light elements (low atomic number) appear darker.

The EDX procedure identifies and quantifies the elemental composition of a specimen. EDX spectrum shows different peaks corresponding to the elements that are present in the sample.

For the two types of analyses, treated specimens were prepared with under the optimum water content conditions obtained with the compaction tests and after the curing process previously described.

\section{Results and discussion}

The results for the compaction tests are presented next. The bearing capacity values (CBR) are discussed later, focusing on the influence of the confinement conditions, the dosages of the additive and the performance of the treated-sand. This section concludes with the microstructural evaluation of the improvement.

\subsection{Compaction performance of aeolian sand stabilized with polymer emulsion}

The results of the different compaction tests developed for the three contents of polymer emulsion are presented in Fig. 2, where the dotted lines correspond to the two tests undertaken for each percentage of polymer, while the solid line corresponds to the average result in each case, including the untreated material for sake of comparison. In all cases, the curves obtained for 

for the optimum water content - dry density for each dosage have been included in the figure. As it can be seen there, the optimum water content of the aeolian sand, without improvement, was found to be $13.7 \%$ and the corresponding maximum dry density equal to $1.630 \mathrm{~kg} / \mathrm{m} 3$ [19]. It is worth to remark again that both values are typical for aeolian sands, according to similar cases reported in the literature [12].

From Fig. 2, a moderate increment of the maximum dry density can be observed for the treated sand respect to the untreated, even for the lowest dosage of polymer emulsion (1630.30 $\mathrm{kg} / \mathrm{m}^{3}$ for the untreated material against $1660.56 \mathrm{~kg} / \mathrm{m} 3$ obtained with $0.5 \%$ of emulsion). However, the dry density only increases very slightly with the increment of dosage (reaching values of $1663.12 \mathrm{~kg} / \mathrm{m}^{3}$ for $1.0 \%$ and $1664.00 \mathrm{~kg} / \mathrm{m}^{3}$ with $1.5 \%$ ). On the other hand, a significant reduction on the optimum water content, ranging from about 9 to $30 \%$, can be observed as the percentage of polymer emulsion increases, following a clear linear trend, as indicated in Fig.3. The best agreement for this linear trend is presented in Eq. 1. As depicted in the figure, the regression coefficient is nearly 1 :

$$
\omega_{\text {opt }}(\%)=-2.95 E_{\text {mul }}(\%)+14.05
$$

where $\omega_{\text {opt }}$ represents optimum moisture content, and $E_{\text {mul }}$ denotes the dosage of additive.

This reduction in the optimum water content of the mixture is potentially a very interesting result since this type of improvement is meant to be applied in arid and semiarid areas, where the water is usually very scarce. Similar trends respect to the optimum water content were reported in several other previous investigations $[38,39]$ for the stabilization of limestone quarry fines with acrylic polymer dispersion, whereas the maximum dry density was reported as slightly decreasing respect to the untreated material, for that material, against as expected. According to the discussion exposed by Onyejekwe and Ghataora [39], the inter-particle friction and the surface tension of the compaction water should be reduced by the addition of a polymer emulsion to a soil, driving more effective compaction, which can be successfully observed in this research.

In general, in the compaction curves of stabilized sand, Fig. 2, an opposite performance can be observed between the dry and wet part of the curve. The dry part of the curve is almost planar, especially for the higher values of dosage, whereas the wet side shows a very pronounced slope, 
almost equal for the three investigated dosages. It must be highlighted that this behavior is not observed in the untreated sand, so this only can be attributed to the addition of the polymer. The planar shape observed in the dry part of the curve can be a beneficial characteristic from an engineering point of view, since, even for very low values of moisture content, respect to the optimum, the variation of the dry density is minimum. On the other hand, it can be noted that the addition of a polymer emulsion, almost independently of the dosage of additive, makes the stabilized sand much more sensitive to an overage in the moisture content once the optimum value has been exceeded, and therefore a slight excess of moisture content respect to the optimum could imply a significant reduction in the maximum dry density. Consequently, it can be concluded that, in desert areas, the stabilization of aeolian sand with polymer emulsion allows to reduce the quantity of water necessary in the compaction.

\subsection{Bearing capacity tests under variable confinement conditions}

4.2.1 CBR results: influence of confinement conditions, energy of compaction and dosage of polymer emulsion

Figure 4 shows the results obtained in all series tested after the CBR procedure previously described. The corresponding results, both laterally confined and under non-confined conditions, as well as the corresponding mean values, are plotted in this figure for the three dosages of polymer emulsion considered in this research. They are represented against the energy of compaction applied in each specimen, i.e. 15, 30 and 60 blows per layer, which correspond to the $25 \%, 50 \%$ and $100 \%$ of the compaction energy established by the reference Modified Proctor test. Moreover, Figs. 5 and 6 show the mean values of CBR achieved from each case, for the two different confinement conditions. Since the untreated material was impossible to be tested without lateral confinement and without a minimum stabilization treatment, only the results corresponding to the untreated material under full confinement condition have been included in both figures for sake of reference.

From Figs. 4 to 6 , it can be observed that the addition of emulsion has a positive effect on the bearing capacity of Jeddah aeolian sand. This effect increases as the percentage of emulsion does so, although in different quantity depending on the degree of confinement. The improvement ranges from null CBR in the case of untreated sand up to a CBR value of around 50 for the $1.5 \%$ 
of additive for the unconfined condition, whereas for the confined cases, the CBR ratios are around 11 for the non-stabilized material up to around 160 for the highest dotation of polymer emulsion. As expected, the benefits of the increment of dosage in the bearing capacity are higher when the lateral confinement is considered. This phenomenon could also be observed by means of the indices of improvement adopted in the next section. The improvement on the bearing capacity with the increment of dotation of additive increases slightly with the rise of compaction energy applied, especially for the confined cases, whereas for unconfined tests, the energy of compaction has very limited influence. In any case, the variation of CBR with the number of blows (energy of compaction) is not substantial.

From Fig. 6 , it must be highlighted that for the lowest dosage of additive, i.e. $0.5 \%$, without confinement, it is possible to achieve an improvement in the bearing capacity of this material equal to the one for confined, untreated material. Therefore, it can be concluded that the addition of a minimal dotation of polymer emulsion can substantially alter the behaviour of the material and improve drastically its bearing capacity. On the other hand, from Fig. 4, it can be observed that the dispersion in the CBR results increases as the percentage of the additive does for the confinement tests but not for the unconfined cases.

As it has been discussed before, in all cases (Figs. 5 and 6), the values of the obtained modified CBR are very similar for the three levels of energy applied in the test. Due to this almost constant response in terms of bearing capacity, the average of the CBR values obtained with the three compaction energies has been adopted for each condition of confinement and dosage. This parameter has been named as MmCBRC and MmCBRU (as defined in [19]) for confined and unconfined conditions, respectively. The corresponding results are included in Table 3 and Fig. 7.

The variation of the parameters MmCBRC and MmCBRU with the dotation of additive follow clear linear trends. In both cases, the correlation coefficients of the linear agreements of MmCBRC and MmCBRU are almost 1, and the corresponding regressions are given by Eqs. 2 and 3. 
From Fig. 7, it is worth noting that the parameters MmCBRC and MmCBRU clearly increase with the increment of dotation of additive but in a more relevant manner when it is combined with high lateral confinement conditions (MmCBRC). Moreover, it must be highlighted that, although the MmCBRU obtained after the addition of this stabilizer without lateral confinement is lower than in the confined tests (MmCBRC), it is enough for many geotechnical applications, as for example, to be employed as grade and subgrade. Thus, it can be noted that the efficiency of this treatment, regarding soil bearing capacity, is clearly satisfactory even under the most disadvantaged conditions of confinement.

\subsubsection{Indices of improvement}

For evaluating the degree of improvement achieved in terms of increment in the bearing capacity of the soil after the treatment with polymer emulsion, compared with the untreated sand, two coefficients have been employed. They have been previously verified with this aim for quantifying the improvement induced by the use of other stabilizers [19]. These coefficients are named as UBCx (Unconfined Bearing Capacity index) and CBCx (Confined Bearing Capacity index) for confined and unconfined conditions, respectively, and they are defined for a particular dosage of polymer emulsion in Eqs. 4 and 5.

$$
U B C_{x i}=\frac{M m C B R U_{x}}{M m C B R C_{O}}
$$

$$
C B C_{x i}=\frac{M m C B R C_{x}}{M m C B R C_{0}}
$$

where MmCBRUx denotes the CBR value obtained from the modified bearing capacity test previously defined, under unconfined conditions, whereas MmCBRCx is the equivalent for confined tests; $\mathrm{x}$ is the percentage of polymer emulsion, and MmCBRO is the corresponding CBR obtained for confined samples of untreated sand. The obtained values are included in Table 3 and represented in Fig. 8 against the dotation of additive.

By means of these indices, it is also possible to confirm one of the most advantageous goals highlighted before: even for the lowest percentage of emulsion considered, the index UBC is nearly 1 , which means that thanks to the addition of a minimal dotation of polymer emulsion, the treated samples achieve, at least, the same bearing capacity as that for untreated sand under confined conditions. This can be considered as an excellent achievement of this improvement 
technique, as it means that the main problem of this material, which is the lack of bearing capacity under low or null lateral confinement conditions, is totally overcome with the only addition of $0.5 \%$ of polymer emulsion. Moreover, as this content increases, the improvements reached are much higher, following an almost perfect linear correlation, as it can be observed in Fig. 8. The linear agreement correlations obtained from these results are expressed in the Eqs. 6 and 7. On the other hand, these indices also confirm that for equal dotation of polymer emulsion, the improvement induced in the soil respect to the untreated sand is significantly higher under confined conditions, which is more remarkable as the dotation of additive increases.

\subsubsection{Curves load-displacement from modified CBR}

One of the most relevant findings observed from the CBR tests is the load-displacement curves, which are scarcely analysed in detail in the literature. These curves are given in Figs. 9 and 10 for every dotation of polymer, three different energies of compaction (15, 30 and 60 blows per layer), and for confined and unconfined conditions. Moreover, the curve obtained for the untreated sand under confined conditions has been also included for reference in Fig. 9.

In all cases, it can be observed that the effect of the energy of compaction is very consistent for all three values of dosages considered. It is worth noting that an increment of the energy of compaction does not necessarily introduce a significant improvement in the bearing capacity, as also happened with the untreated material, neither under confined nor unconfined conditions. However, the behaviour of confined and unconfined specimens is in fact absolutely different, as it is self-evident from the comparison of Figs. 9 and 10.

In the case of confined conditions, Fig. 9, the peak load applied raises significantly from the untreated material (around $2.5 \mathrm{kN}$ ) compared to the stabilized material, even for the lowest dotation of additive (higher than $10 \mathrm{kN}$ ). On the other hand, while the curves for $1.0 \%$ and $1.5 \%$ present a monotonic increment, the curve for $0.5 \%$ dotation shows a progressive increment until reaching a maximum value of load, which corresponds to a displacement around 7.5 to $10 \mathrm{~mm}$, followed by an abrupt reduction in the load until the residual strength of the stabilized soil. It is 
remarkable that this behaviour can be only observed for the lowest dotation of polymer emulsion but not for higher percentages of additive, or even for the untreated material. Thus it can be observed that the addition of a minimal dotation of polymer emulsion in conjunction with high levels of lateral confinement, converts the soil into a more brittle material compared with the untreated sand; however as the dotation of polymer emulsion raises, the stabilized soil turns into a material with a more ductile response. On the other hand, the maximum load that it is possible to achieve in each case increases with the dotation of additive, following the same trend as for increasing displacements.

In the opposite case, Fig. 10 for unconfined condition, there is a significant and progressive transformation in the performance of the mixture (load-displacement curve) as the percentage of the polymer emulsion is incremented. For the three dosages, the shape of the curve loaddisplacement exhibits a very similar pattern. This is defined by a linear and quick increment at the very beginning of the curve, followed by a plate shape in the curve, with almost constant loading (given by the peak value), and ending with an abrupt decrement in the load until reaches a very low residual load, maintaining this value until the end of the test. Particularizing for every dotation of polymer considered, it is obtained that for the curve of $0.5 \%$ of additive, the maximum load displacement, whereas in the cases for $1.0 \%$ and $1.5 \%$ of polymer emulsion, the maximum load raises up to $5 \mathrm{kN}$ and $8 \mathrm{kN}$, and the horizontal stage is stretched until $5 \mathrm{~mm}$ and $7.5 \mathrm{~mm}$, respectively. Consequently, the higher the dotation, the wider the plate zone of the loaddisplacement curve. Therefore, from this figure, it can be pointed out that the stabilization of aeolian sand with polymer emulsion under unconfined conditions transforms the response of the mixture into a material with a brittle failure followed by a residual strength. However, as the dotation of polymer emulsion is incremented, the brittle failure of the material occurs for higher values of displacement, which can be assimilated as a higher ductile behavior. Similar tendencies were also reported by other researchers [37].

Finally, it is very convenient to compare the curve load-displacement obtained for the percentage of $0.5 \%$ without confinement and the curve for the untreated material under confined condition. Although similar CBR ratios are obtained in both cases, both figures reveal an absolutely different behavior of the material, since it exhibits a more ductile response in the 

figures, it can be observed that the maximum load (around $2.5-3 \mathrm{kN}$ in both cases) is obtained for different values of displacement, around $1.5 \mathrm{~mm}$ for the $0.5 \%$-unconfined case and around 5 $\mathrm{mm}$ for the untreated-confined specimen. What implies that the displacement necessary is more than three times higher in the second case, which means that the material is more ductile than in the first one.

The patterns of behaviour represented in Fig. 9 and 10 are also related to the modes of failure observed in the tested samples. All specimens tested in the mold (under confined condition) presented a classical punching shear failure below the piston due to the penetration. However, in the unconfined specimens, a radial cracking pattern was observed, started from the piston point of application. As the load applied was higher, the number and size of cracks were incremented until reaching a complete fragmentation of the specimen into isolated blocks. After that, the lateral confinement contribution was significantly reduced, which corresponds to the abrupt decrement and residual strength responses observed in Fig. 10. Moreover, the higher the dotation of polymer emulsion, the slower development of the cracking network, because the lateral confinement was maintained and the sample could support higher loads and displacements before failing, as can also be observed in Fig. 10.

From the analysis and comparison of the curves load-displacement obtained during the penetration stage of the CBR test of the stabilized specimens, it can be observed that the addition of polymer emulsion (in different dosages) contributes to improving the bearing capacity of the soil. Moreover, the type of response of the soil is modified, making this more brittle or ductile pattern depending on the particular dotation of additive combined with the degree of lateral confinement. This is one of the most remarkable findings observed for the use of this polymer emulsion as the stabilizer for this particular type of sand.

\subsection{Microstructural characterization}

\subsubsection{Scanning Electron Microscopy (SEM)} dosage of polymer emulsion after the curing process are shown in Fig. 11. In this figure, SEM findings are organized for each percentage of polymer emulsion (in rows), and both 500x (left 

side) and 1000x (right side). These images reveal the modification induced in the microstructure

531 of the soil after adding different percentages of additive respect to the sand without treatment. As can be observed from Fig. 11-a and b (untreated specimen), each particle is completely isolated one to each other, without any bonding or connection between them, so each one can be easily identified and the disaggregation of the material is evident. Moreover, the surface of each grain is absolutely clean without any substance over it. Figs. 11-c to 11-h show the progressive microstructural changes triggered by the increment of polymer emulsion. As it increases, bonding an aggregation levels rise too, making possible to achieve a more compact and stable structure, far from the disaggregated pattern of the original untreated soil. Similar behaviours have also been observed by other researchers [39]. The particles were linked by filaments of polymer emulsion which are coating their surfaces and generated new bonds between them. Details of bonds of polymer emulsion can be observed in Fig. 11-i and Fig. 11-j.

It is evident that the number and size of polymer filaments increase as the dosage of polymer emulsion is higher because a higher proportion of each particle surface can be enveloped by the polymer emulsion. However, the compactness of the structure is not significantly modified by varying the content of the emulsion. Consequently, the internal structure of untreated specimen is significantly altered by the additive, displaying aggregation and turning into a slightly denser structure, almost independently of the percentage of additive though. This behaviour has also been observed from the compaction test, where the maximum dry density of the treated specimen is higher than the untreated sample, but minimal increments in dry density can be observed between different dosages of additive.

On the other hand, the polymer threads between particles are responsible for the aggregation of particles and the new stable structure of the aeolian sand. Thanks to them, the bearing capacity with the low-confinement condition can be reached. Moreover, as the dotation of polymer emulsion increases, the number and size of polymer filaments do so, so the connexions between particles are bigger and stronger. This observation is in agreement with the bearing capacity results, especially in unconfined condition. 
Three EDX spectra are shown in Fig. 12-a to Fig. 12-c, for the untreated sand, a polymer filament and a sample with a $1.5 \%$ of polymer emulsion, respectively. As can be observed in the untreated sample (Fig. 12-a), oxygen (43.37\%) and silicon (41.14\%) are the main elements due to the quarzitic nature of the aeolian sand, while carbon (10.65\%) is less abundant. In contrast, in the case of the polymer filament (Fig. 12-b), the more abundant components are carbon (51.92 $\%)$, oxygen $(28.28 \%)$ and silicon $(12.16 \%)$. In the case of the treated sample with a dosage of $1.5 \%$ of polymer emulsion (Fig. 12-c), the spectrum reveals that, as expected, the content of carbon is significantly higher in the mixture compared with the original sand, due to the addition of polymer $(20.44 \%)$. The content of oxygen was similar in the treated and untreated samples, while the percentage of silicon was logically reduced. The percentage of other secondary elements, like calcium, also increased with the polymer emulsion. EDX spectroscopy reveals the modifications introduced in the final chemical composition of the stabilized sand, and also confirms that the strands or threads that linked the grains of sand in Fig. 11 correspond to the polymer emulsion.

\section{Conclusions}

The experimental results obtained after the stabilization of aeolian sand (collected from Jeddah, Saudi Arabia) with a vinyl acrylic, polymer emulsion, along with their analyses and discussion, are presented in this paper. Different dosages of additive, ranging from 0.5 to $1.5 \%$ (as no higher dosages were possible to test for this particular sand) have been evaluated in order to analyse the improvement reached in the mixture in terms of compaction and bearing capacity of this type of soil under different lateral confinement conditions. This aspect has been scarcely investigated in the literature. In particular, two extreme situations have been tested: specimens completely confined and specimens without any lateral confinement. The main derived conclusions are summarised next: dry density, independently of the dotation of additive considered. The dry parts of the compaction curve become almost horizontal. This can be profitable in practical situations, since the final weight of any geo-structures constructed with this stabilized sand will not raise significantly respect to the untreated material. However, as the dotation of polymer 
emulsion increases, the maximum dry density is achieved for lower water contents, up to a reduction of $30 \%$ for the highest dotation of polymer emulsion considered in this research (1.5\%). Undoubtedly, this is a very interesting finding for the utilization of aeolian sand in construction of geo-structures in arid areas, where the water is normally very scarce.

- The curing conditions of the specimen exhibit a great influence on the response of the soil, especially in terms of bearing capacity. In order to achieve the maximum contribution of the polymer emulsion in the stabilization of the sand, it is necessary to guarantee that the additive has been dried completely before testing the specimens. In order to achieve this, a rigorous curing procedure needs to be undertaken. In this particular case, this goal was reached by drying the samples in the oven under $40^{\circ} \mathrm{C}$ (similar to weather conditions in desert areas), until obtaining a constant weight over time.

601

- Both confined and unconfined bearing capacity values obtained with the modified CBR procedure described in this paper, demonstrate a very significant improvement for this aeolian sand when is treated with polymer emulsion. The results are particularly remarkable in the case of unconfined condition, for which the disadvantaged effect of removing the lateral confinement vanishes when the dotation of emulsion is as little as $0.5 \%$, reaching a bearing capacity ratio very close to the one obtained for the untreated sand under full lateral confinement conditions. Moreover, in both cases, the bearing capacity is almost independent of the energy of compaction used.

- The improvement observed in the bearing capacity after the treatment shows an increasingly monotonic linear trend with the dotation of polymer emulsion, although the improvement is clearly more significant for the confined case respect to the unconfined situation. This phenomenon can also be observed by means of the CBC and UCB indices adopted in this research, which are proven to be a very suitable, representative an easy way to evaluate the improvement in the bearing capacity of stabilized aeolian sand, because they consider both the dotation and the influence of lateral confinement.

- The addition of a polymer emulsion (in different dosages) also modifies the response of the soil behavior from more brittle to a more ductile response as the dotation is higher, 

specimens.

- From SEM analysis, it can be observed that the polymer emulsion transforms the isolated particles of sand into a particle aggregation and consequently in a more stable structure. The bonds between particles develop by means of filaments of polymer between particles. The number and size of these filaments are more abundant as the percentage of additive is higher. They are the responsible of the successful behavior observed in term of bearing capacity, especially for low confined condition. The compactness of the aggregated structure does not significantly vary with the percentage of additive, in accordance with the observed results from the compaction tests.

The experimental results presented in this paper support that relevant improvements on the engineering properties of aeolian sand can be obtained after its stabilization with low dosages of polymer emulsion. Therefore, this additive can be firmly considered as a suitable alternative to the traditional stabilizers. It can also be taken into consideration for the stabilization of other

\section{Acknowledgements}

The help received from Ms. Begona Perez-Moraga and Dr. Edrees El-Helaly on the search, collection and acquisition of the sand from Jeddah (Saudi Arabia) during the initial stages of this research is gratefully appreciated. The authors would also want to express their gratitude to the firm Composan Industrial y Tecnologia, S.L. for supplying the additive employed in this research and also for their technical assistance. Thanks also to the SAIUEx service for the EDX and SEM analyses.

\section{References}

[1] Das, B.M., (2007). Principles of foundation engineering. Toronto: Thompson.

[2] El-Sayed, M.I., (1999). Sedimentological characteristics and morphology of the aeolian sand dunes in the eastern part of the UAE: a case study from Ar Rub' Al Khali. Sedimentary Geology,123:219-38. 
[3] Khan, I. H., (1982). Soil studies for highway construction in arid zones. Engineering Geology, 19, 47-62.

[4] Al-Sanad, H.A. and Bindra, S.P., (1984). Soil mechanics for road engineers in Arabian Peninsula. Kuwait University, Kuwait.

[5] Abu Seif, E. S., (2013). Performance of cement mortar made with fine aggregates of dune 650 sand, Kharga Oasis, Western Desert, Egypt: an experimental study. Jordan Journal of Civil Engineering, 7 (3), 270-284.

652

[6] Abu-Zeid, M. M., Baghdady, A. R. and El-Etr, H. A., (2001). Textural attributes, mineralogy 653 and provenance of sand dune fields in the greater Al Ain area, United Arab Emirates. Journal of Arid Environments, 48 (4), 475-499.

656

[7] Yuan, Y., Wang, X. and Zhou, X., (2008). Experimental research on compaction 657 characteristics of aeolian sand. Frontiers of Architecture and Civil Engineering in China, 2 (4), 359-365.

[8] Al-Ansary, M., Pöppelreiter, M. C., Al-Jabry, A. and lyengar, S. R., (2012). Geological and physiochemical characterization of construction sands in Qatar. International Journal of Sustainable Built Environment, 1, 64-84.

[9] Padmakumar, G. P., Srinivas, K., Uday, K. V., lyer, K. R., Pathak, P., Keshava, S. M. and Singh, D. N., (2012). Characterization of aeolian sands from Indian desert. Engineering Geology, 139-140, 38-49.

[10] Al-Taie, A. J., Al-Shakarchi, Y. J. and Mohammed, A. A., (2013). Investigation of geotechnical specifications of sand dune: a case study around Baiji in Iraq. International Journal of Advanced Research, 1 (6), 208-215.

[11] Baghdadi, Z. A. and Rahman, M. A., (1990). The potential of cement kiln dust for the stabilization of dune sand in highway construction. Building and Environment, 25 (4), 285289.

[12]Elipe, M.G.M. and Lopez-Querol, S. (2014). Aeolian sands: characterization, options of improvement and possible employment in construction - The State-of-the-art. Construction and Building Materials, 73, 728-739.

[13]Aiban, S. A., (1994). A study of sand stabilization in eastern Saudi Arabia. Engineering Geology, 38, 65-79. 
[14] Al-Aghbari, M. Y. and Dutta, R. K., (2005). Suitability of desert sand cement mixes for base courses in highway pavements. Electronic Journal of Geotechnical Environment, 10 (D).

[15] Moosavi, K. and Kalantari, B., (2011). Improving load bearing capacity of wind-blown sand using ordinary Portland cement. Electronic Journal of Geotechnical Environment, 16(Q), 1267-1274.

[16] AlKarni, A. and ElKholy, S. M., (2012). Improving geotechnical properties of dune sands through cement stabilization. Journal of Engineering and Computer Sciences, 5 (1), 1-19.

[17] Albusoda, B. S. and Salem, L. A., (2012). Stabilization of dune sand by using cement kiln dust (CKD). Journal of Earth Sciences and Geotechnical Engineering, 2 (1), 131-143.

[18] Ghrieb, A., Mitiche-Kettab, R. and Bali, A., (2013). Stabilization and utilization of dune sand in road engineering. Arabian Journal for Science and Engineering, 39, 3, 1517-1529.

[19] Lopez-Querol, S., Arias-Trujillo, J., Elipe, M. G. M., Matias-Sanchez, A. and Cantero, B., (2017). Improvement of the bearing capacity of confined and unconfined cement-stabilized aeolian sand. Construction and Building Materials, 153, 374-384.

[20]Dunn, C. S. and Salem, M. N., (1971). Influence of processing procedures on strength of sand stabilized with cationic bitumen emulsion. Highway Research Record, No. 351. National Research Council, Washington, D.C., 50-65.

[21]Akili, W. and Monismith, C. L., (1978). Permanent deformation characteristics of cementemulsion stabilized sand. Proceedings of the Assoaciation of Asphalt Paving Technologists, 47, 281-301.

[22] Fatani, M. N. and Sultan, H. A., (1982). Dune sand-aggregate mixes and dune sand-sulfur 696 mixes for asphalt concrete pavement. Transportation Research Record, No. 843. National Academy of Science, Washington, D.C., 72-79.

[23] Al-Halhouli, A. R., (1986). Evaluation of emulsified asphalt treated sand for road bases. M. S. Thesis, Department of Civil Engineering, KFUPM, Dhahran.

[24] Arora, M. G. and Arabiat, T., (1986). Evaluation of asphalt emulsion treated mixtures for road bases. Proceedings of the $13^{\text {th }}$ ARRB/5 $5^{\text {th }}$ REAAA, 209-213. asphalt-treated sand for low-volume road and road bases. Transportation Research Record, 
[26] Sabbagh, A. O., (1988). Design and viscoelastoplastic characterization of a lime-dune sandasphalt mix. Proceedings of the $3^{\text {rd }}$ IRF Middle East Regional Meeting, 3175-3188.

[27] Al-Abdul Wahhab, H. I. and Abduljauwad, S. N., (1989). A study of soil stabilization in the Eastern Province of Saudi Arabia. Proceedings of the $1^{\text {st }}$ IRF World Meeting, 3, 117-120.

[28] Al-Abdul Wahhab, H. I. and Asi, I. M., (1997). Improvement of marl and dune sand for highway construction in arid areas. Building and Environment, 32 (3), 271-279.

[29] Asi, I. M., Al-Abdul Wahhab, H. I., Al-Amoudi, O. S. B., Khan, M. I. and Siddiqi, Z., (2002). Stabilization of dune sand using foamed asphalt. Geotechnical Testing Journal (ASTM), 25 (2), 168-176.

[30] Al-Abdullah, S. F. I., (2006). An approach in improving the properties of sand dunes. Journal of Engineering, 13, 930-939.

[31] Lahalih, S. M. and Ahmed, N., (1998). Effect of new soil stabilizers on the compressive strength of dune sand. Construction and Buildings Materials, 12, 321-328.

[32] Freer-Hewish, R. J., Ghataora, G. S. and Niazi, Y., (1999). Stabilization of desert sand with cement kiln dust plus chemical additives in desert road construction. Proceedings of the Institution of Civil Engineers - Transport, 135, 29-36.

[33] Al-Khanbashi, A. and El-Gamal, M., (2003). Modification of sandy soil using water-borne polymer. Journal of Applied Polymer Science, 88, 2484-2491.

[34] Al-Khanbashi, A. and Abdalla, S. W., (2006). Evaluation of three waterborne polymers as stabilizers for sandy soil. Geotechnical and Geological Engineering, 24, 1603-1625.

[35]Zandieh, A. R. and Yasrobi, S. S., (2010). Study of factors affecting the compressive strength of sandy soil stabilized with polymer. Geotechnical and Geological Engineering, 28, 139-145.

[36] Homauoni, Z. J. and Yasrobi, S. S., (2011). Stabilization of dune sand with poly(methyl methacrylate) and polyvinyl acetate using dry and wet processing. Geotechnical and Geological Engineering, 29, 571-579.

[37] lyengar, S. R., Masad, E., Rodriguez, A. K., Bazzi, H. S., Little, D. and Hanley, H. J. M., (2013). Pavement subgrade stabilization using polymers: characterization and performance. Journal of Materials in Civil Engineering, 25, 4, 472-483. 
[38] Onyejekwe, S. and Ghataora, S. (2015). Soil stabilization using proprietary liquid chemical stabilizers: sulphonated oil and a polymer. Bulletin of Engineering Geological Environment, $74,651-665$

[39] Onyejekwe, S. and Ghataora, S. (2016). Stabilization of quarry fines using a polymeric additive and Portland cement. Journal of Materials in Civil Engineering, 28,1.

[40]ASTM D2487 - 11. Standard Practice for Classification of Soils for Engineering Purposes (Unified Soil Classification System).

[41]AASHTO M 145 - 82 (1991). Standard Specification for Classification of Soils and SoilAggregate Mixtures for Highway Construction Purposes.

[42] COMPOSAN (2013). Ficha Técnica, Sistema CompoSolid. http://www.composanindustrial.com/resources/archivosbd/productos documentos/e3210f111 05c8e1a13bb35071c60b971.pdf (accessed on 09/04/2018 - in Spanish).

[43] UNE 103501, Geotecnia. Ensayo de compactación. Proctor modificado (in Spanish). (Equivalent to: ASTM D1557-12. Standard Test Methods for Laboratory Compaction Characteristics of Soil Using Modified Effort.), 1994.

[44] UNE 103502, Método de ensayo para determinar en laboratorio el índice C.B.R. de un suelo (in Spanish). (Equivalent to: ASTM D1883-16. Standard Test Method for California Bearing Ratio (CBR) of Laboratory-Compacted Soils.), 1995. 


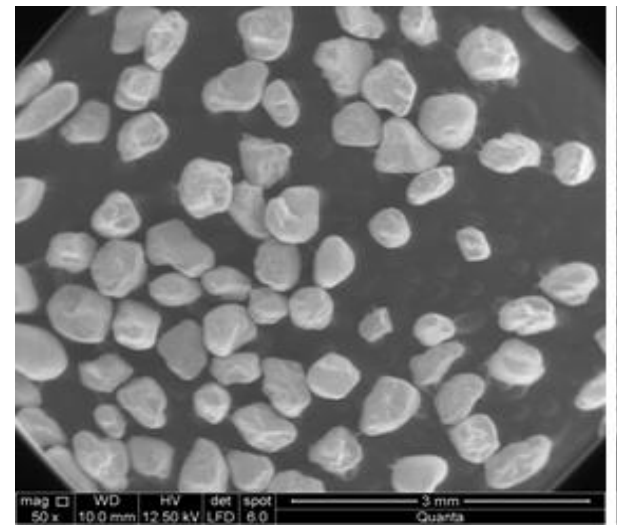

a)

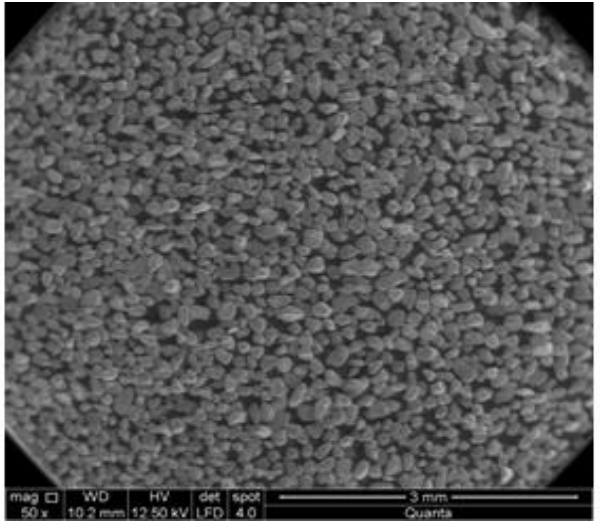

b)

753 Figure 1. Electronic microscope: 50x micrographs for Jeddah aeolian sand. a) Y-1G: fraction with

754 particle size greater than $0.160 \mathrm{~mm}$; b) $\mathrm{Y}-1 \mathrm{~F}$ : fraction with the finest particle size, smaller than $7550.160 \mathrm{~mm}[19]$. 


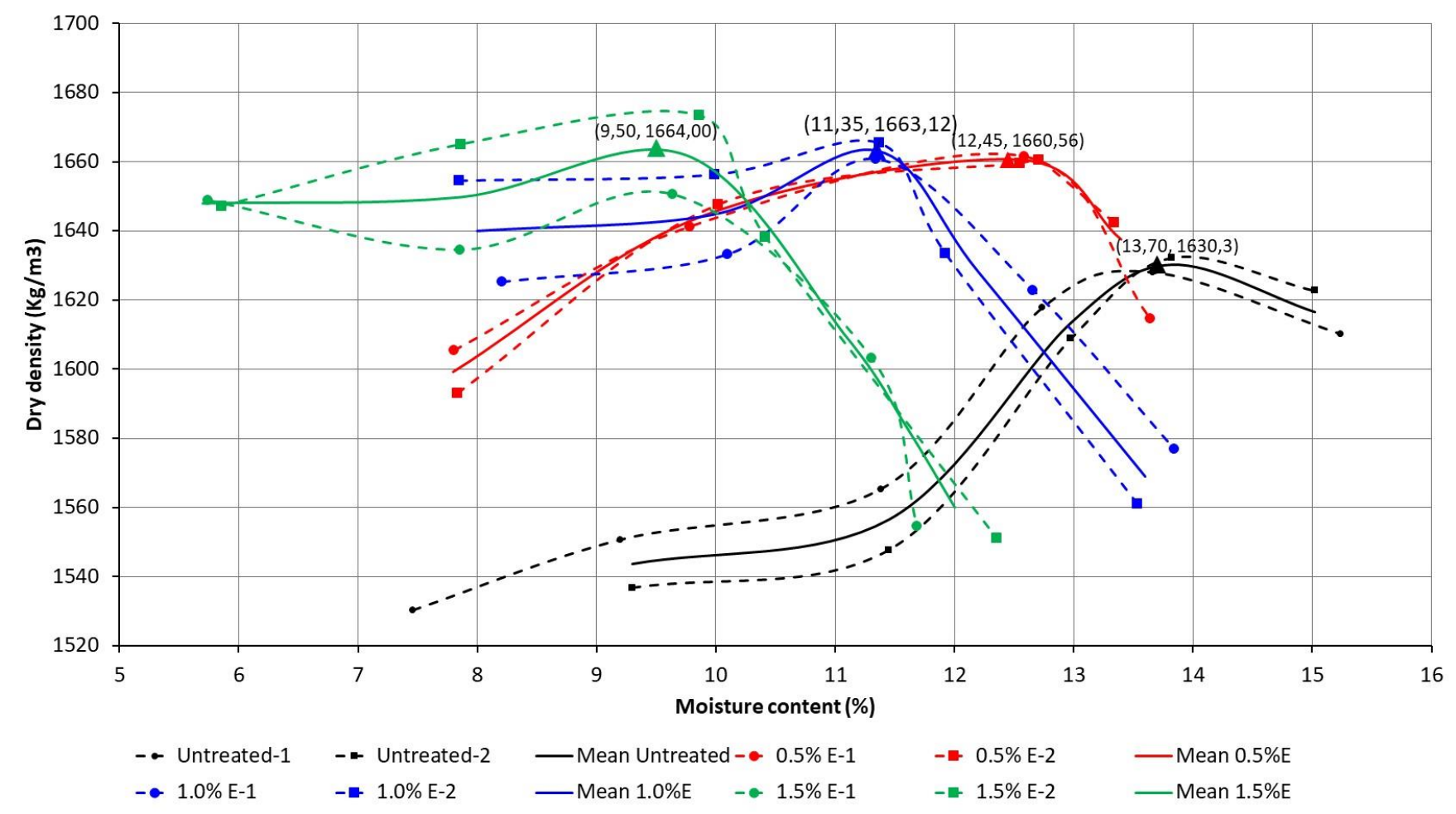

759 Figure 2. Compaction curve of Jeddah Aeolian sand for different dosages of polymeric emulsion

760 respect to the untreated sand. (Notation: $\mathrm{X} \% \mathrm{E}-\mathrm{Y}, \mathrm{X}$ is the percentage of emulsion investigated

761 whereas $Y$ denotes the corresponding number of set of tests and "mean" denotes the average results in each case). 


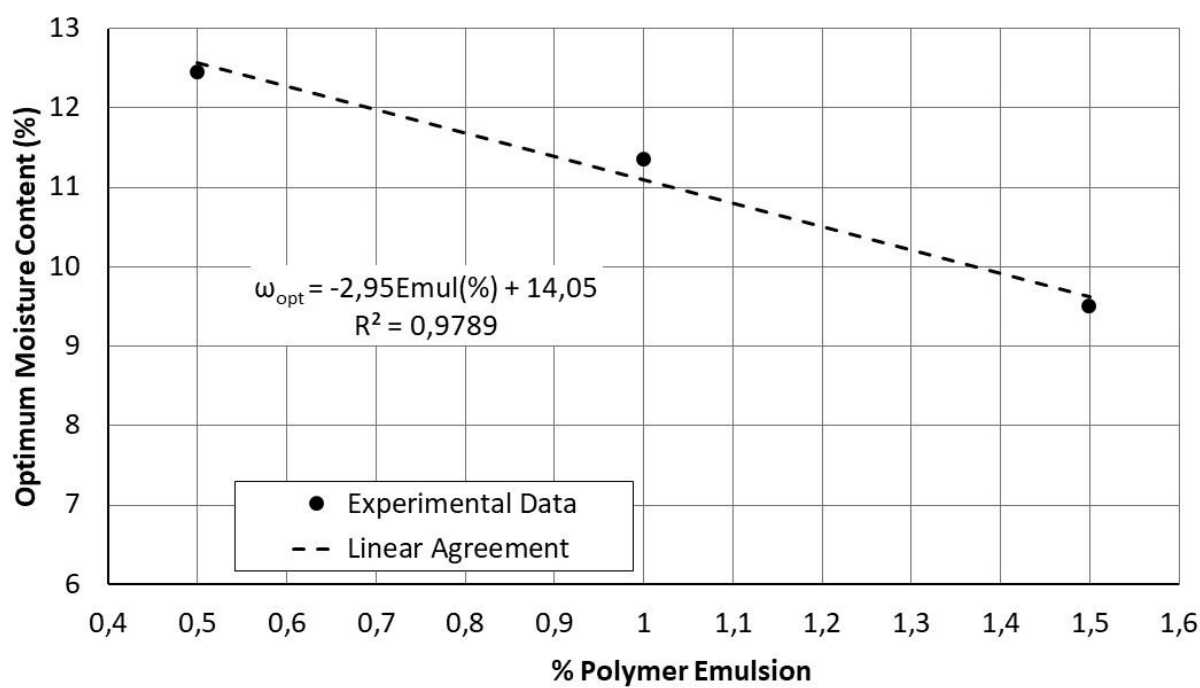

766

767

768 Figure 3. Variation of optimum water content respect to the percentage of polymer emulsion 769 investigated. 

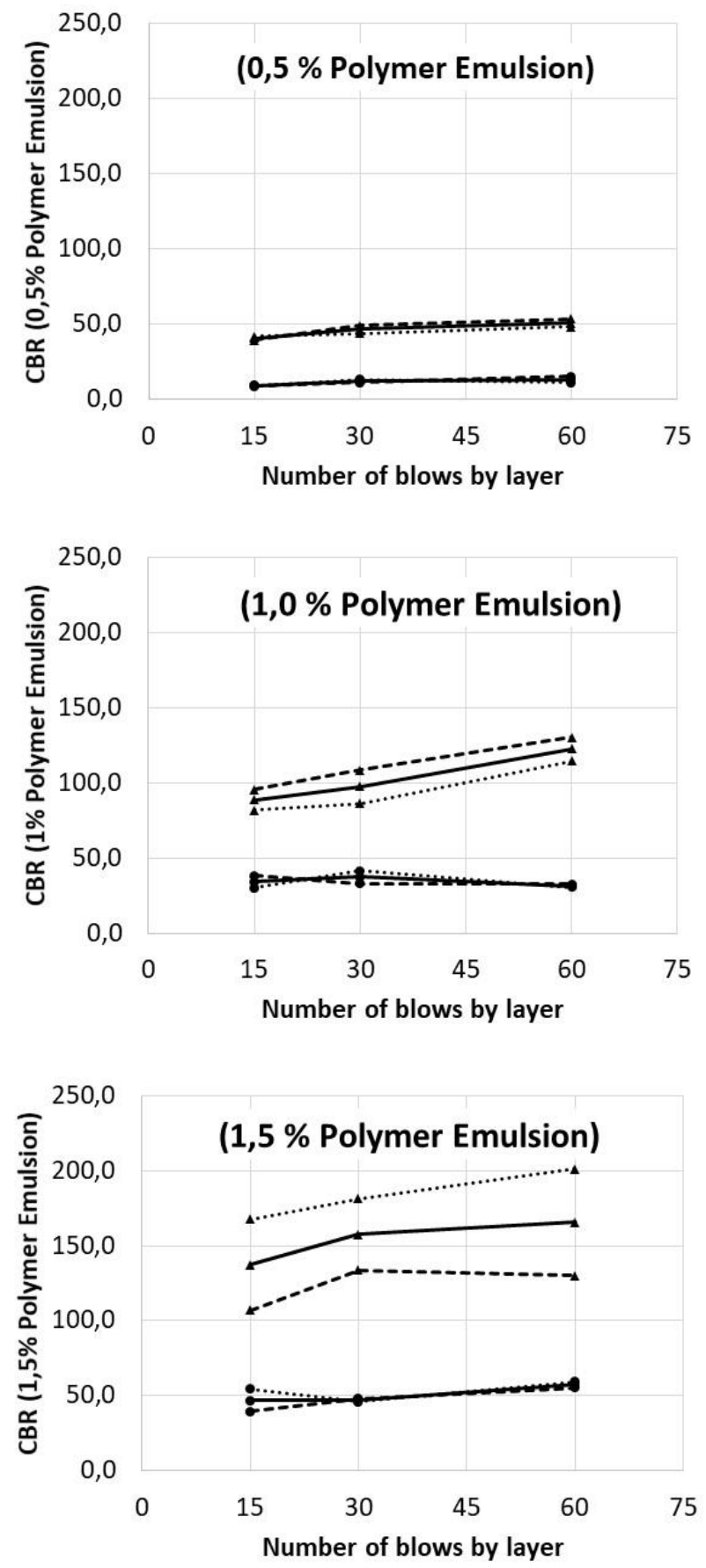

$$
\begin{aligned}
& \text {..... Unconfined E-1 } \\
& \text {..... Confined E-1 } \\
& \rightarrow-\text { Unconfined Mean } \longrightarrow \text { - Confined E-2 } \\
& \rightarrow \text { Confined Mean }
\end{aligned}
$$

776 Figure 4. CBR ratios obtained in each series of specimens tested for each percentage of polymer emulsion under both confined and unconfined condition and the corresponding mean values. 


\section{Confined - Condition}

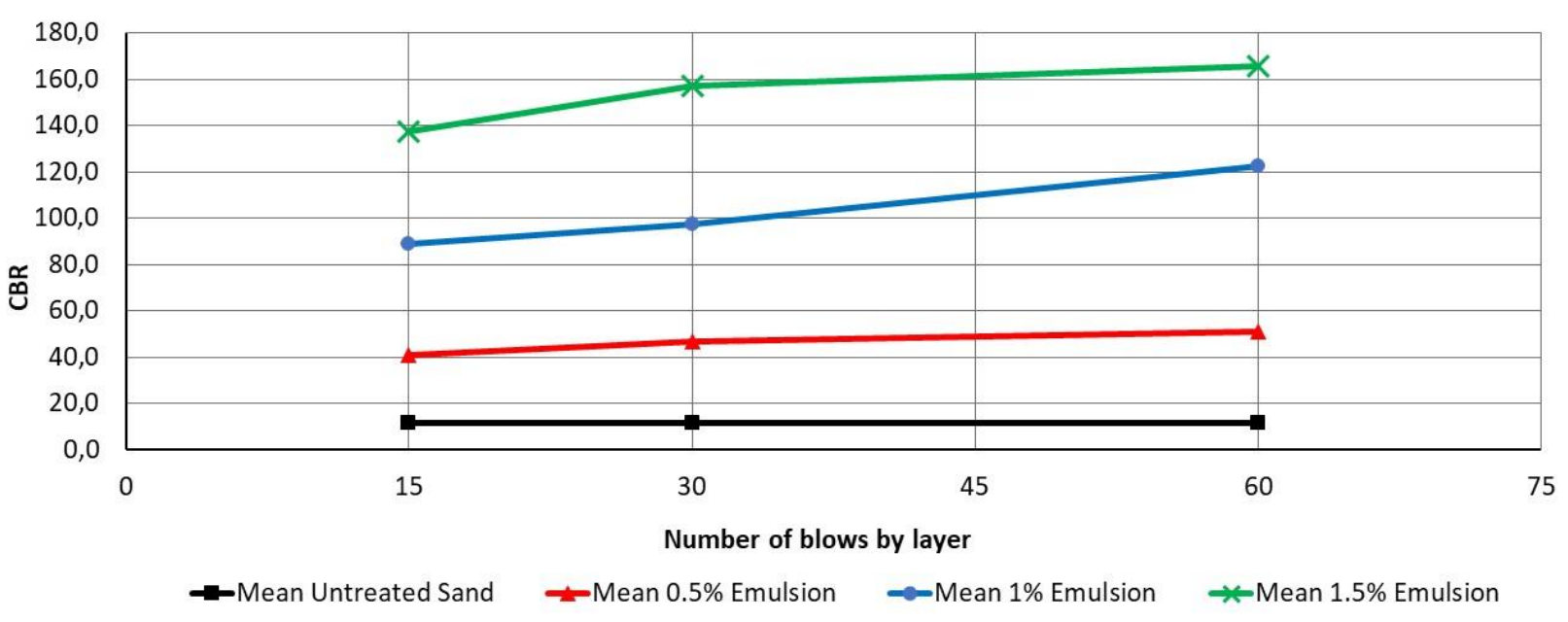

781 Figure 5. Confined conditions: variation of bearing capacity results (mean values) obtained after modified CBR tests respect to the compaction energy applied, for different percentages of polymeric

783 emulsion, from $0.5 \%$ to $1.5 \%$, and for untreated material. (15, 30 and 60 blows by layer represent 25 $\%, 50 \%$ and $100 \%$, respectively, of the corresponding proctor compaction energy). 


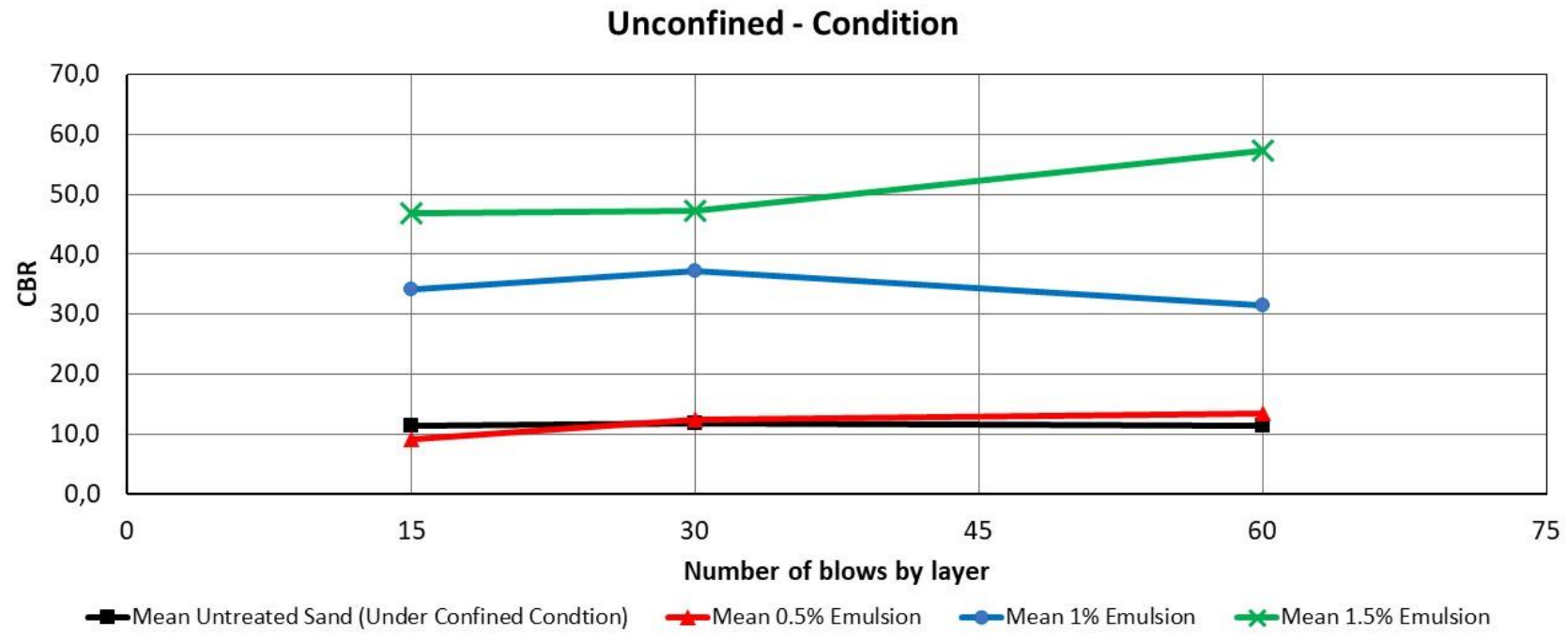

786

787

788 Figure 6. Unconfined conditions: variation of bearing capacity results (mean values) obtained after modified CBR tests respect to the compaction energy applied, for different percentages of polymeric emulsion, from 0.5 to $1.5 \%$. The results obtained for untreated specimens under confined conditions

791 have been maintained for comparison purposes. (15, 30 and 60 blows by layer represent $25 \%, 50 \%$ and $100 \%$, respectively, of the corresponding proctor compaction energy). 


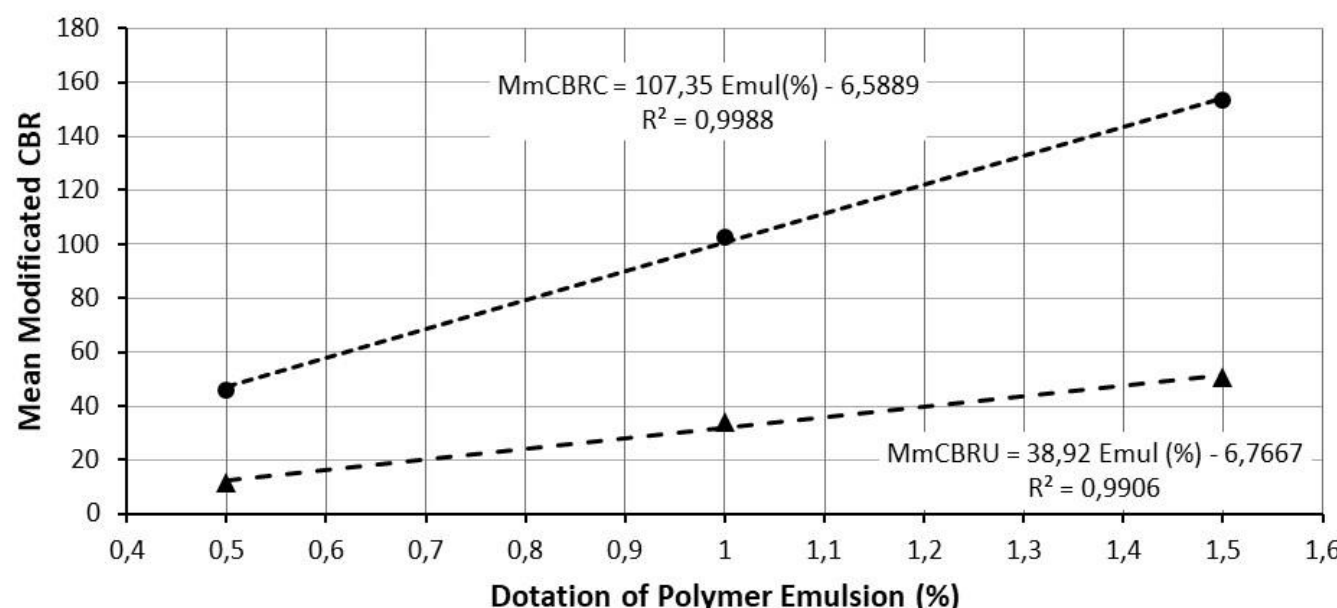

- Confined \ Unconfined -----Linear agreement-Confined - - Linear agreement-Unconfined

799 Figure 7. Mean values of CBR tests under confined and unconfined conditions (MmCBRC and

$800 \mathrm{MmCBRU}$ ) related to the dotation of polymeric emulsion. Linear trends are also included 801 (discontinuous lines). 


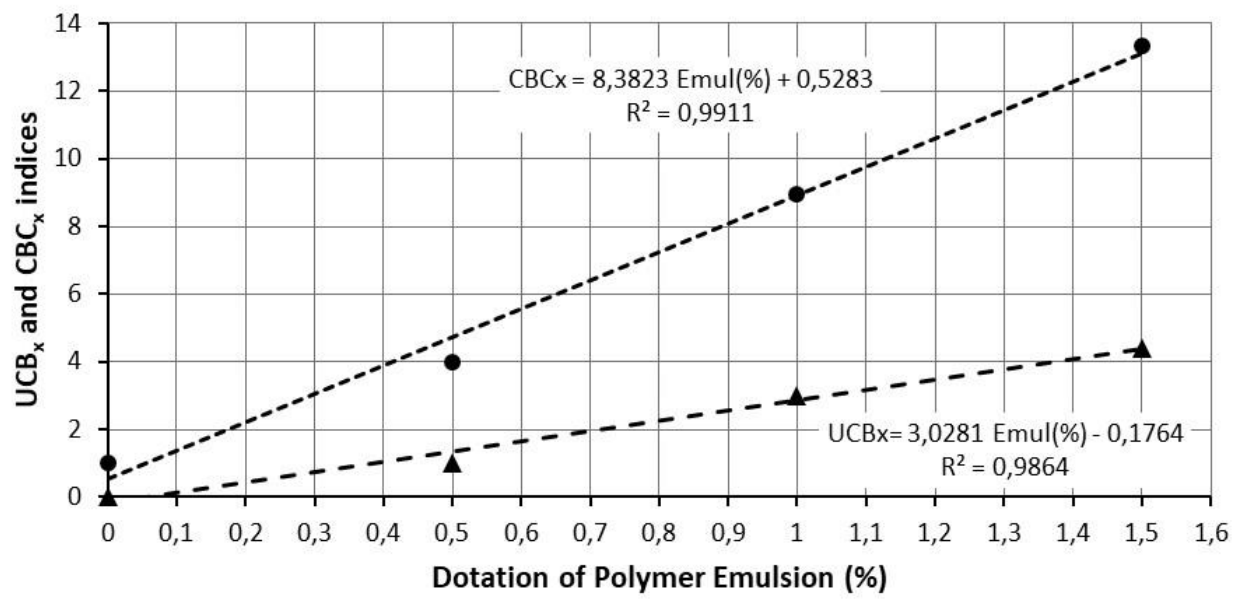

804

- $\mathrm{CBCx}$ \ UCBx - - - Linear agreement (CBCx) - Linear agreement (UCBx)

805 Figure 8. Evolution of the indices $\mathrm{UBC}_{\mathrm{x}}$ for unconfined bearing capacity condition and $\mathrm{CBC}_{\mathrm{x}}$ for

806 confined bearing capacity condition, for the different percentages of polymer emulsion considered.

807 Linear tendencies are also included (discontinuous lines). 
809
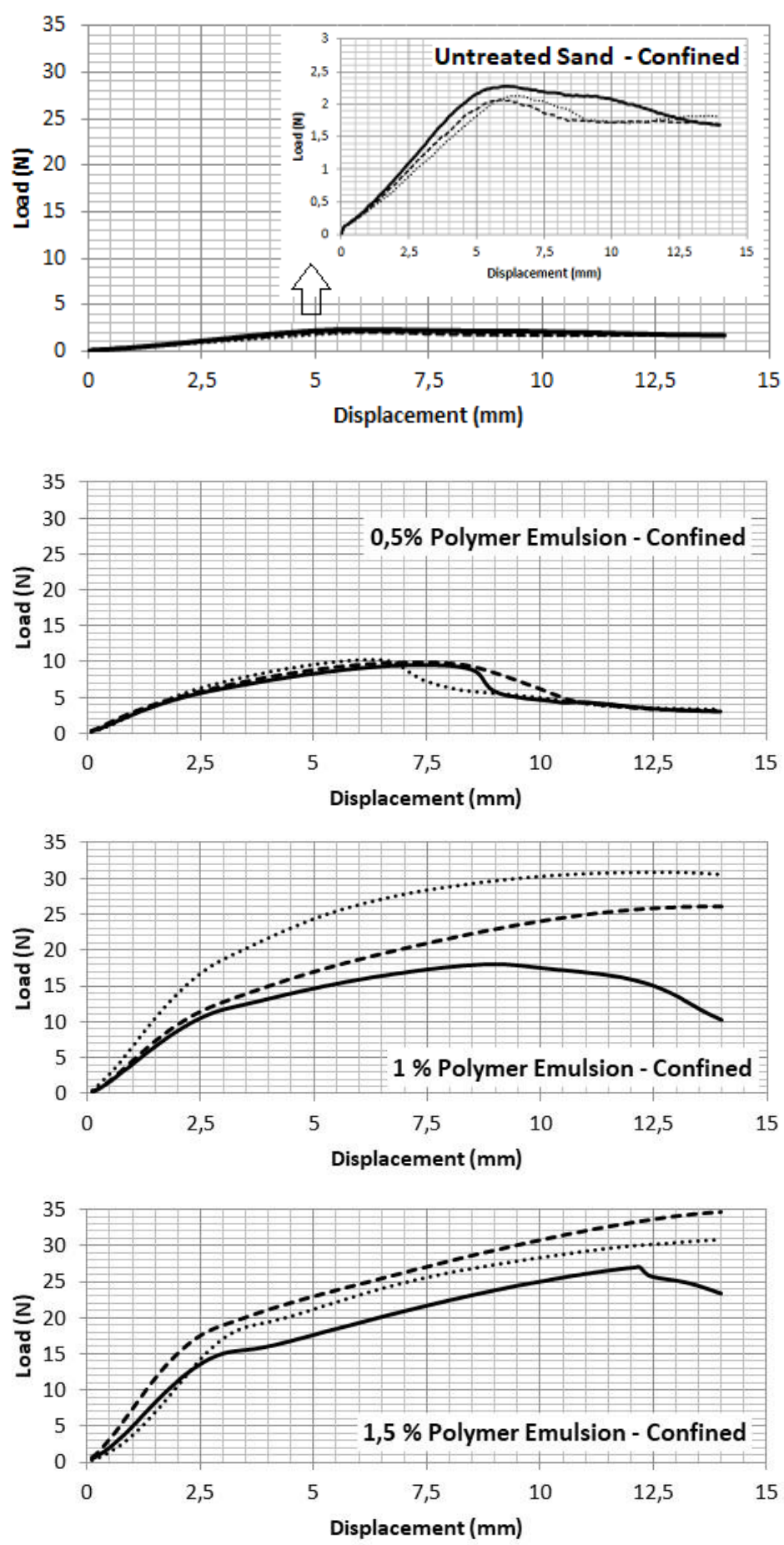

814 Figure 9. Confined specimens: curves load-displacement obtained after the penetration stage in modified CBR tests, under different compaction energies (blows by layer), for the three dotation of polymer emulsion $(0.5 \%, 1.0 \%$ and $1.5 \%)$ and also for untreated sand 


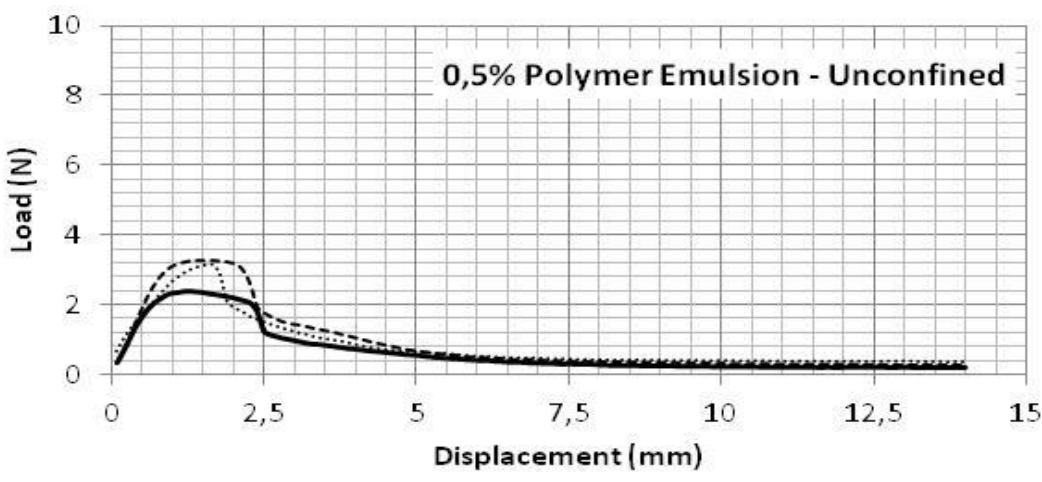

819

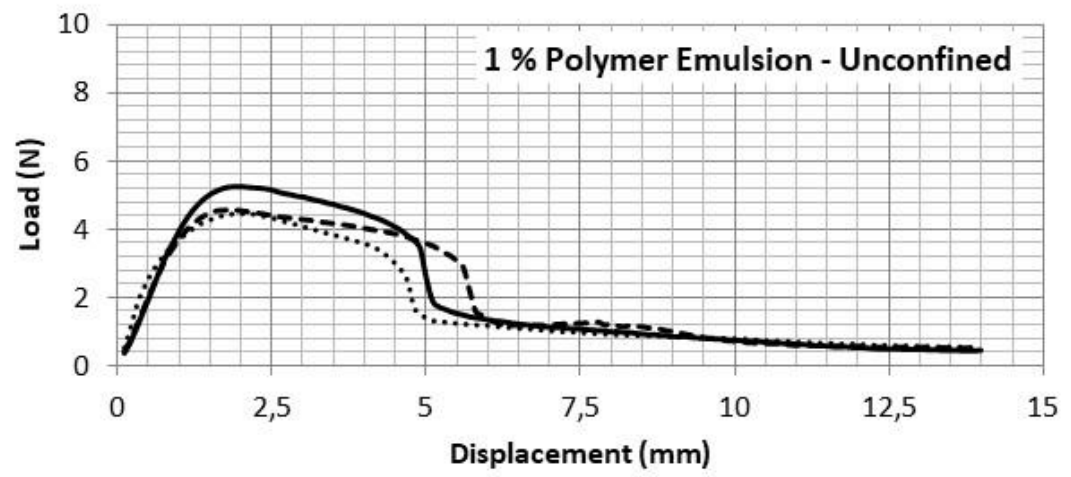

820

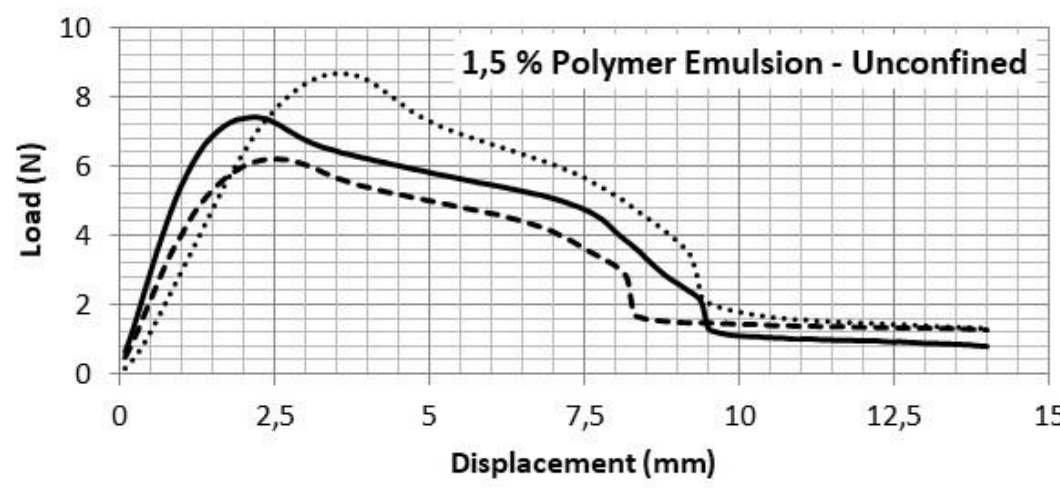

823 Figure 10. Unconfined specimens: curves load-displacement obtained after the penetration stage in 824 modified CBR tests, under different compaction energies (blows by layer), for the three dotation of polymer emulsion $(0.5 \%, 1.0 \%$ and $1.5 \%)$ (unconfined test for untreated sand not possible to execute). 


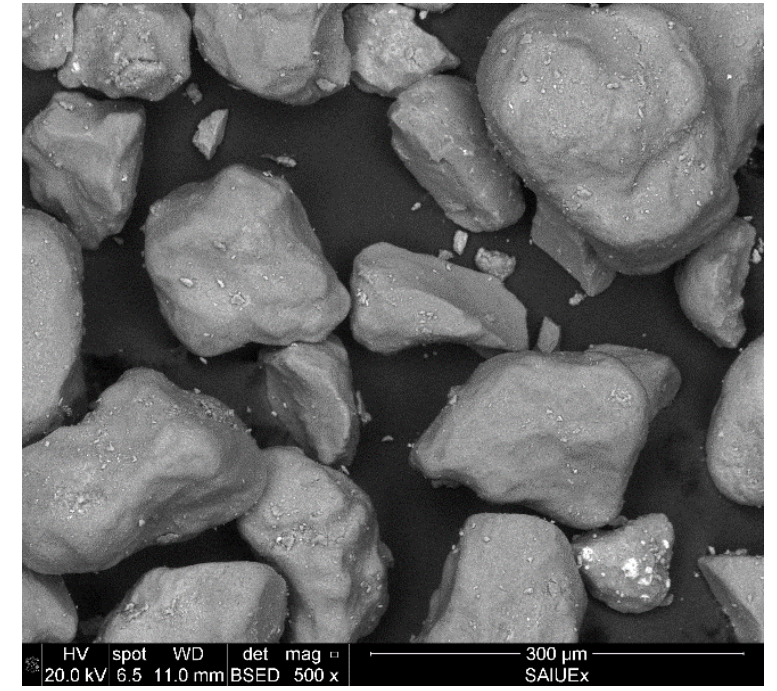

a) Untreated Sand 500x

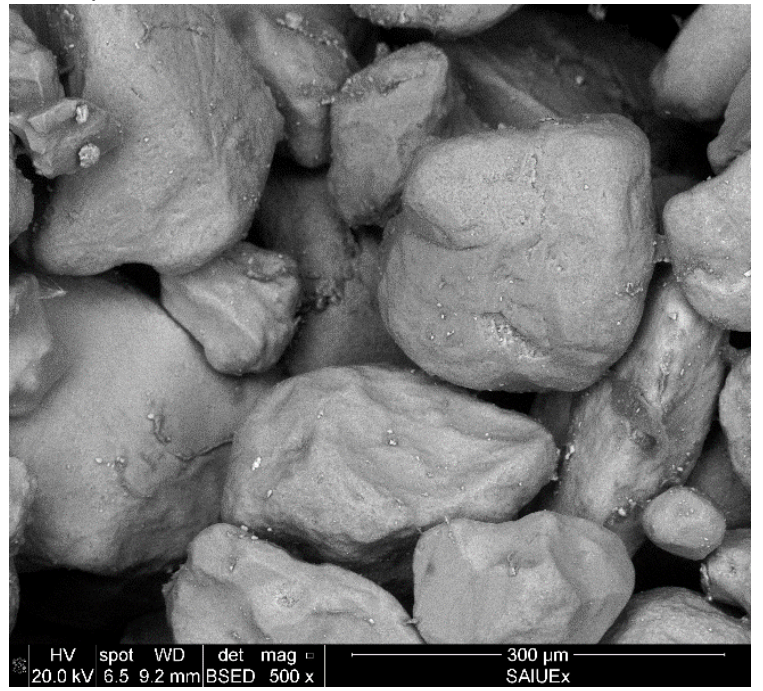

c) $0.5 \%$ Polymer Emulsion 500x

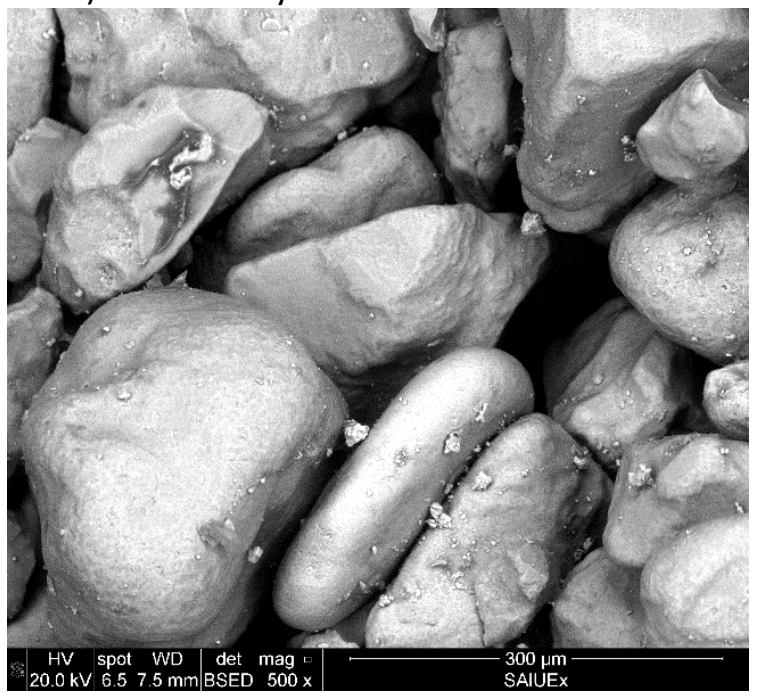

e) $1 \%$ Polymer Emulsion 500x

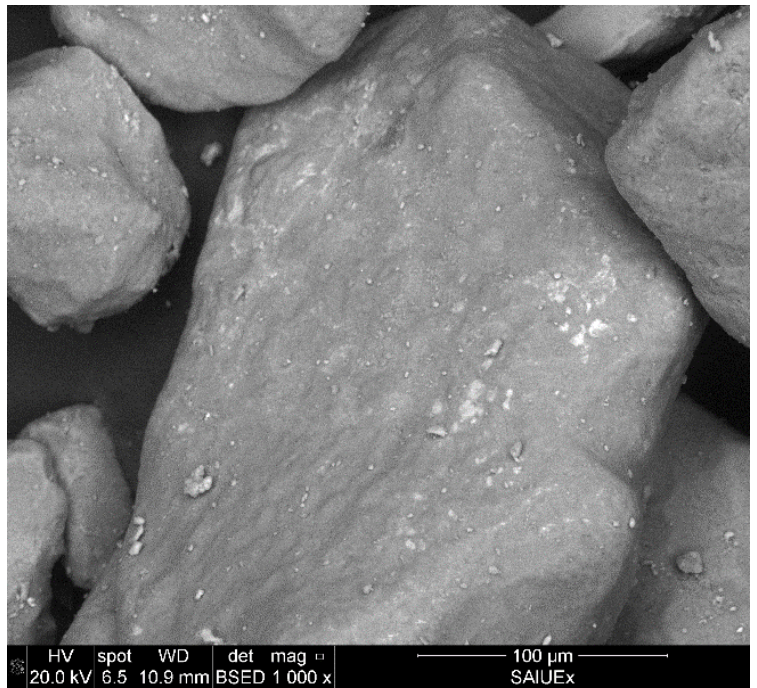

b) Untreated Sand 1000x

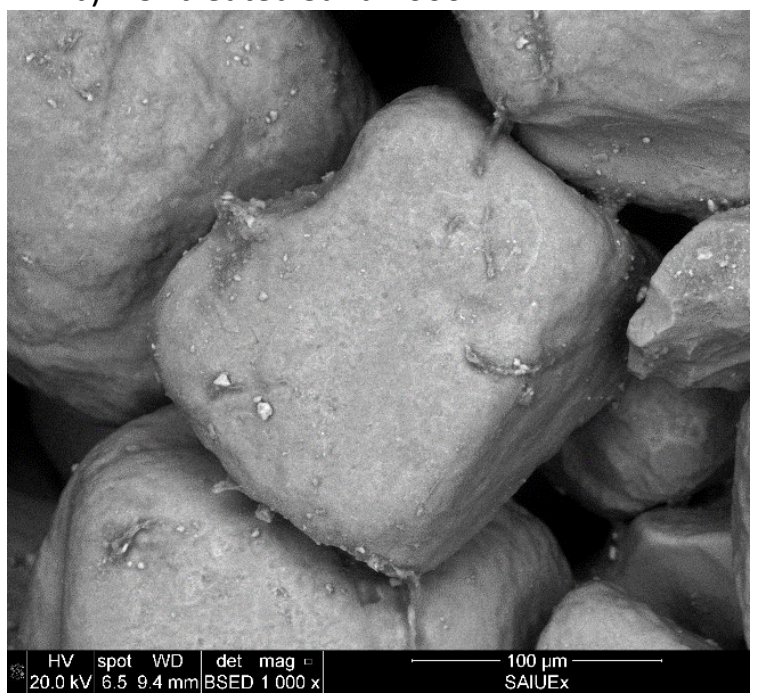

d) $0.5 \%$ Polymer Emulsion 1000x

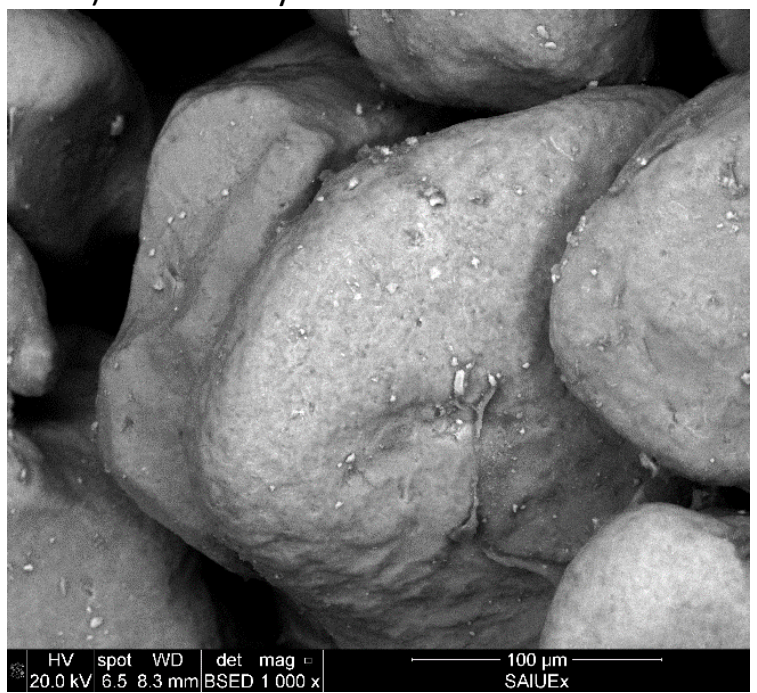

f) $1 \%$ Polymer Emulsion 1000x 


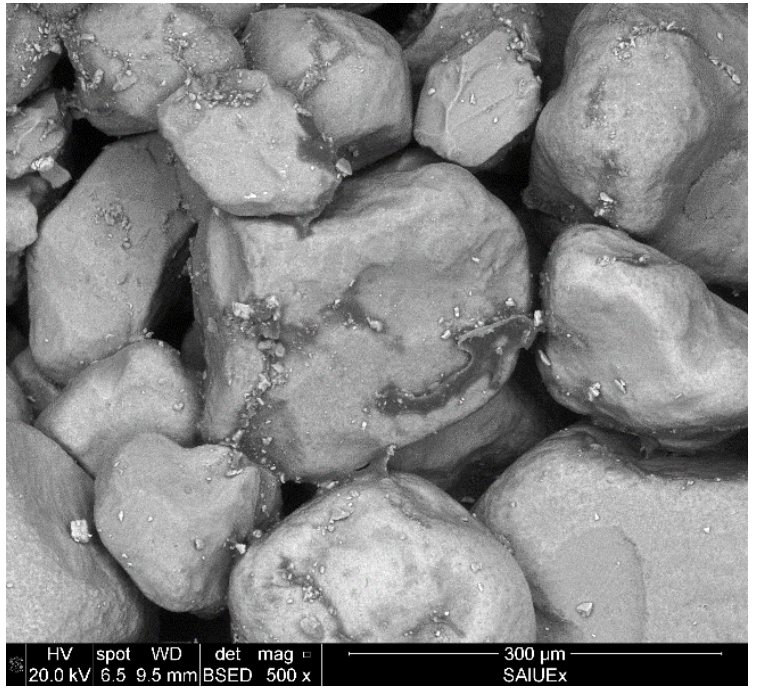

g) $1.5 \%$ Polymer Emulsion 500x

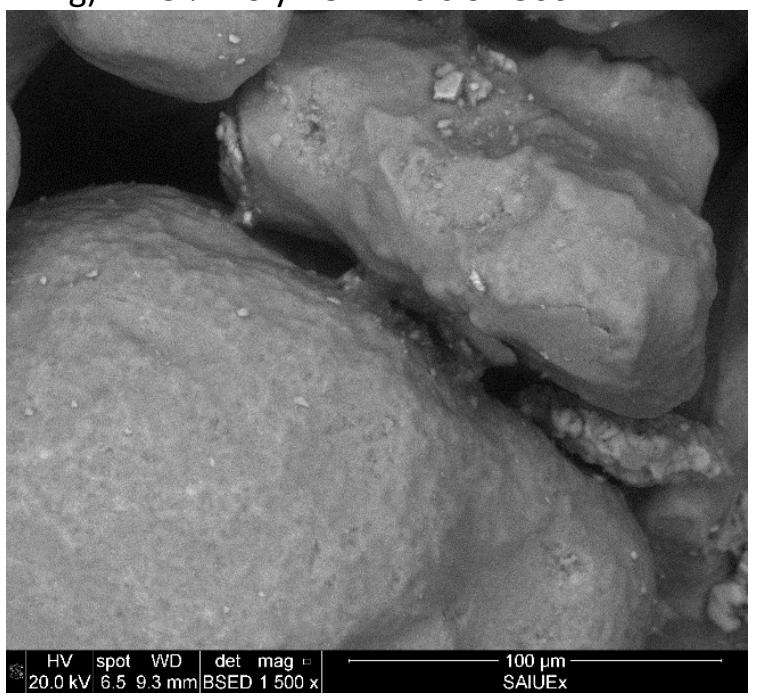

i) Detail of polymer filament $1500 \times(0.5 \%$ Polymer Emulsion-Sample)

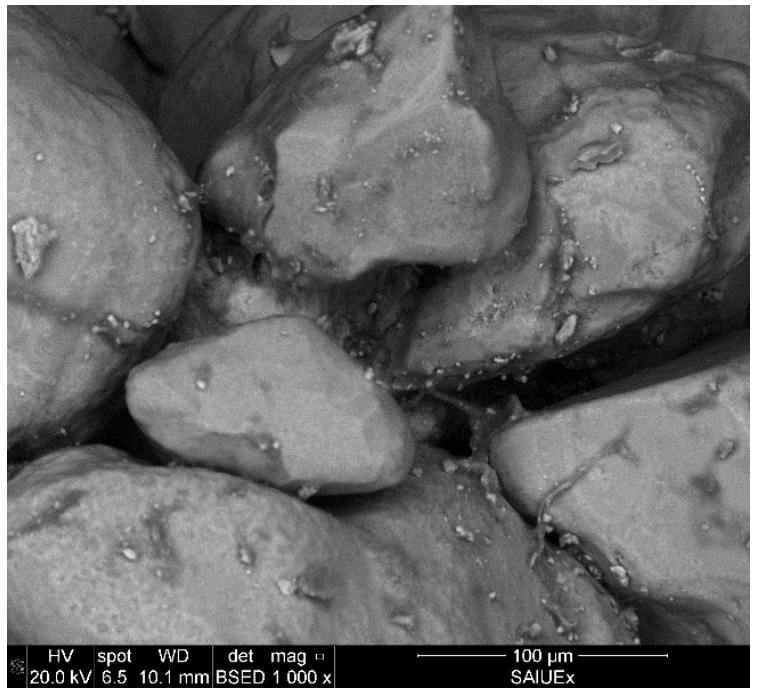

h) $1.5 \%$ Polymer Emulsion 1000x

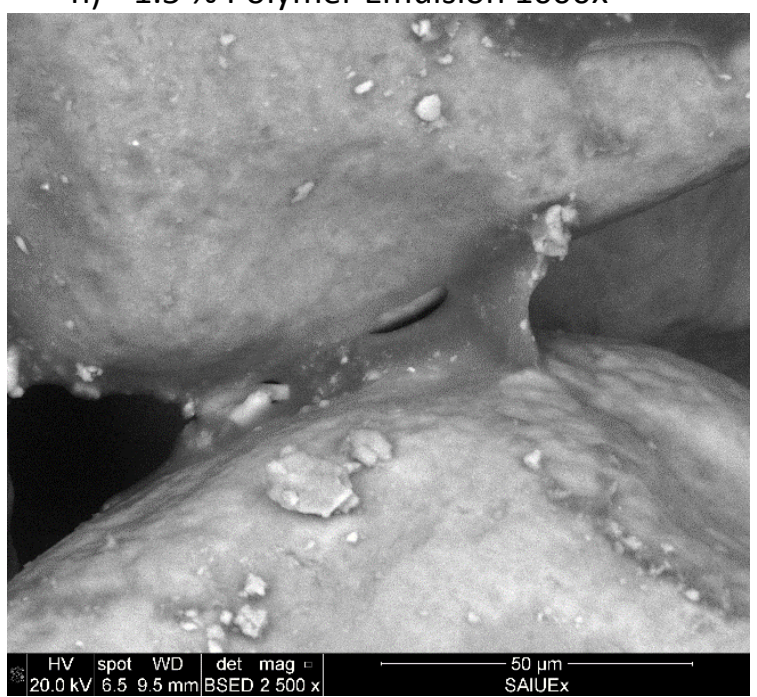

j) Detail of polymer filament 2500x (1.5\% Polymer Emulsion-Sample)

831 Figure 11. Scanning Electron Microscopy (SEM): a) untreated sand 500x; b) untreated sand 1000x;

832 c) $0.5 \%$ Polymer Emulsion 500x; d) $0.5 \%$ Polymer Emulsion 1000x; e) 1 \% Polymer Emulsion 500x;

833 f) $1 \%$ Polymer Emulsion 1000x; g) $1.5 \%$ Polymer Emulsion 500x; h) $1.5 \%$ Polymer Emulsion 1000x;

834 i) Detail of polymer filament 1500x (0.5 \% Polymer Emulsion-Sample); j) Detail of polymer filament 2500x (1.5\% Polymer Emulsion-Sample) 


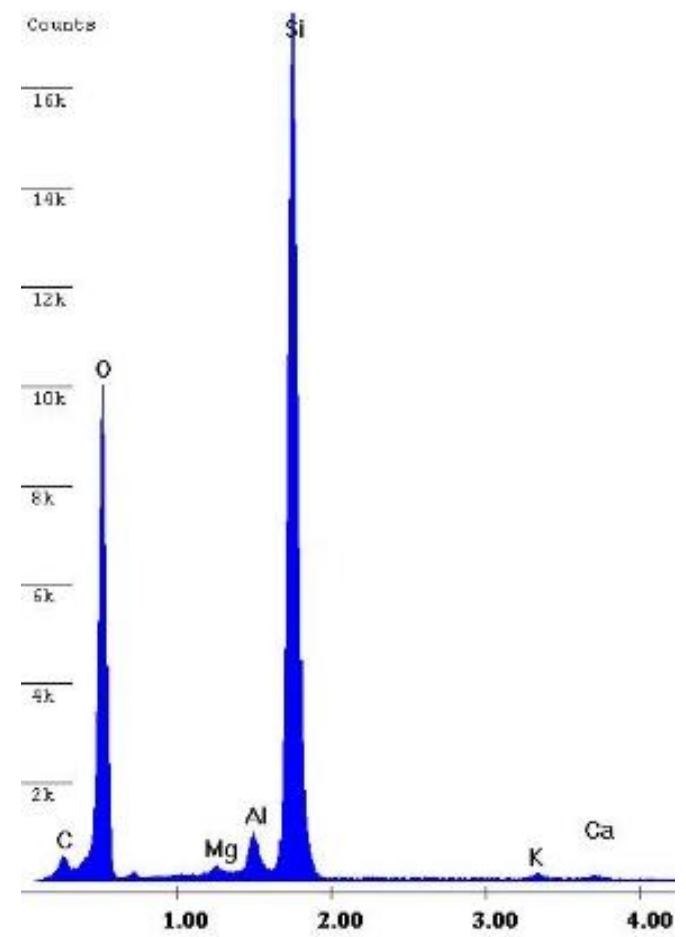

a) Untreated sand

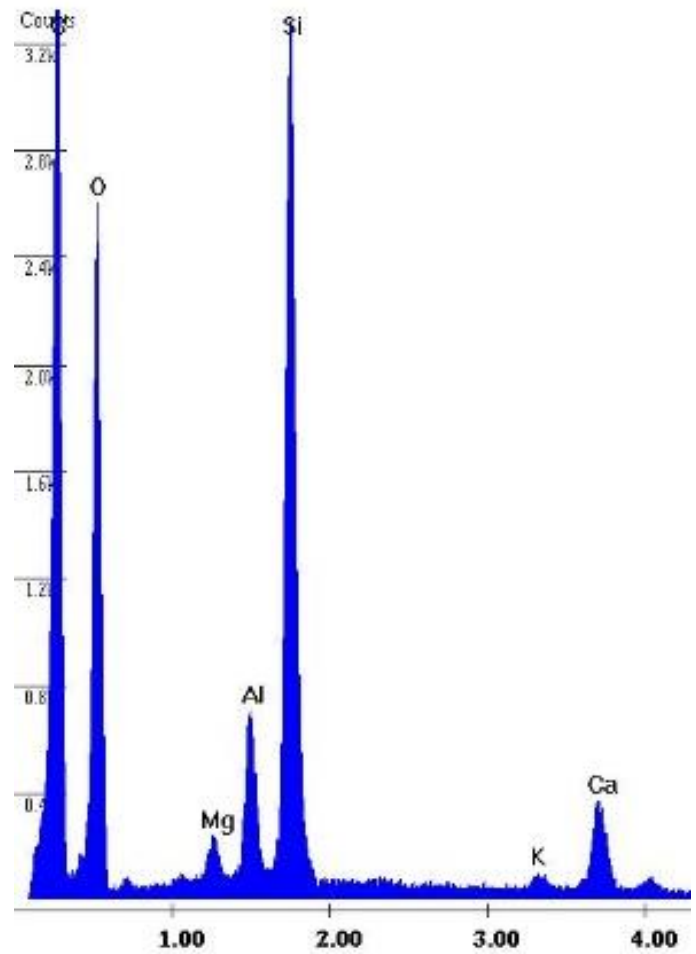

b) Polymer filament 


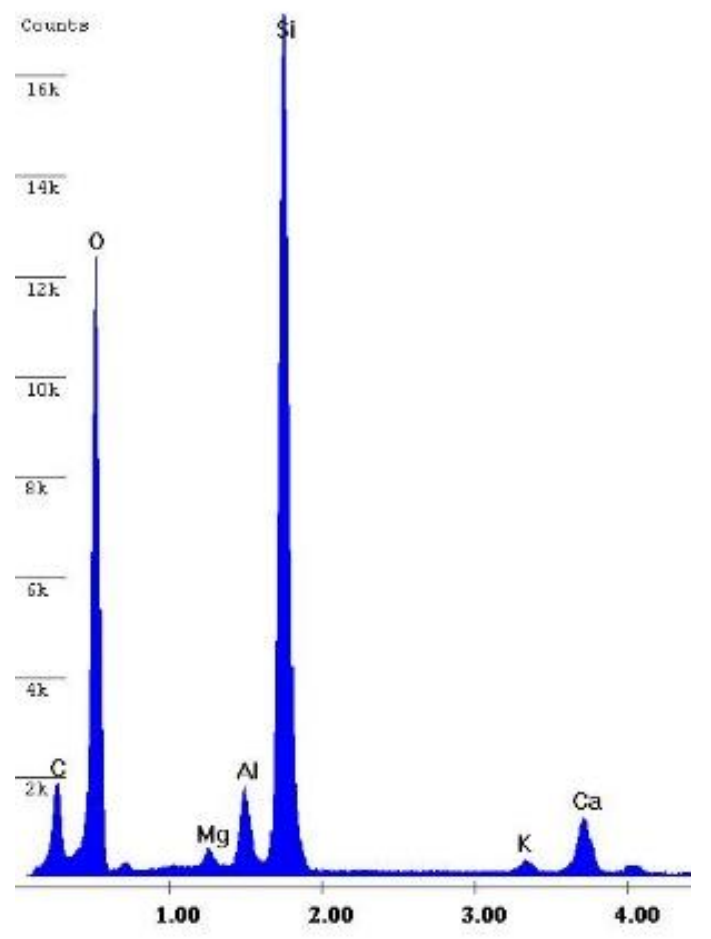

842

c) Treated sand - $1.5 \%$ polymer emulsion

845 Figure 12. Energy-Dispersive X-Ray Spectroscopy (EDX): a) untreated sand; b) polymer filament 846 (different vertical scale); c) treated sand $-1.5 \%$ polymer emulsion 
849 Table 1. Summary of the physical properties of Jeddah aeolian sand (after [19])

\begin{tabular}{|l|l|}
\hline Soil property & Value \\
\hline Specific gravity $\left(\mathrm{G}_{\mathrm{s}}\right)$ & 2.67 \\
\hline Natural moisture content (\%) & 0.27 \\
\hline $\mathrm{D}_{10}(\mathrm{~mm})$ & 0.109 \\
\hline $\mathrm{D}_{30}(\mathrm{~mm})$ & 0.179 \\
\hline $\mathrm{D}_{60}(\mathrm{~mm})$ & 0.258 \\
\hline $\mathrm{C}_{u}$ & 2.37 \\
\hline $\mathrm{C}_{\mathrm{c}}$ & 1.14 \\
\hline Carbonate (qualitative analysis with acid test) & YES \\
\hline Color & Reddish \\
\hline Classification soil (USCS) [40] & SP - Poorly graded sand \\
\hline Classification soil (AASTHO) [41] & A3 \\
\hline
\end{tabular}

850 Note: $D_{10}=$ grain diameter at $10 \%$ passing; $D_{30}=$ grain diameter at $30 \%$ passing; $D_{60}=$ grain diameter at

$85160 \%$ passing; $\mathrm{C}_{\mathrm{u}}=$ coefficient of uniformity; Cc: coefficient of curvature

852 
Table 2. Summary of the main physical and chemical properties of the acrylic polymer emulsion [42]

\begin{tabular}{|l|l|}
\hline Polymer emulsion & Value \\
\hline Type of the polymers used & Acrylic \\
\hline Phase & Liquid \\
\hline Dilution (part of solid vs part of water) & $40 \%$ vs $60 \%$ \\
\hline Density relative to water & 1.04 to 1.15 \\
\hline pH & $4.0-9.5$ \\
\hline Vapor pressure $\left(\right.$ at $\left.20^{\circ} \mathrm{C}\right)$ & $17 \mathrm{~mm} \mathrm{Hg}$ \\
\hline Boiling temperature $\left(^{\circ} \mathrm{C}\right)$ & 100 \\
\hline Color & White and transparent after drying \\
\hline Odor & Acrylic and non-odor after drying \\
\hline
\end{tabular}

854

855 
856 Table 3. Mean values of modified CBR results (MmCBRC and MmCBRU) for the different dosages of 857 polymer emulsion (including the untreated material) for both confined and unconfined tests, and also 858 the corresponding indices $\mathrm{CBC}_{\mathrm{x}}$ and $\mathrm{UBC}_{\mathrm{x}}$

\begin{tabular}{|l|l|l|l|l|}
\hline $\begin{array}{l}\text { Dotation of } \\
\text { Polymer }\end{array}$ & $\begin{array}{l}\text { MmCBRC } \\
\text { (Confined Tests) }\end{array}$ & $\begin{array}{l}\text { MmCBRU } \\
\text { (Unconfined } \\
\text { Tests) }\end{array}$ & $\begin{array}{l}\text { CBC } \\
\text { (Confined Bearing } \\
\text { Capacity index) }\end{array}$ & $\begin{array}{l}\text { (Unconfined } \\
\text { Bearing Capacity } \\
\text { index) }\end{array}$ \\
\hline $\begin{array}{l}\text { Untreated } \\
\text { Aeolian sand }\end{array}$ & 11.51 & $\begin{array}{l}\text { Not possible } \\
(0.00)\end{array}$ & 1.00 & 0.00 (Null) \\
\hline $0.5 \%$ & 46.03 & $11.60 \quad$ & 4.00 & 1.01 \\
\hline $1.0 \%$ & 102.86 & 34.33 & 8.94 & 2.99 \\
\hline $1.5 \%$ & 153.38 & 50.51 & 13.36 & 4.39 \\
\hline
\end{tabular}

859

860

861 